2019-01-07

\title{
Caffeine Exacerbates Postictal Hypoxia
}

\author{
Phillips, Thomas James
}

Phillips, T. J. (2019). Caffeine Exacerbates Postictal Hypoxia (Unpublished master's thesis).

University of Calgary, Calgary, AB.

http://hdl.handle.net/1880/109459

Downloaded from PRISM Repository, University of Calgary 


\title{
UNIVERSITY OF CALGARY
}

Caffeine Exacerbates Postictal Hypoxia

by

Thomas James Phillips

\author{
A THESIS \\ SUBMITTED TO THE FACULTY OF GRADUATE STUDIES \\ IN PARTIAL FULFILMENT OF THE REQUIREMENTS FOR THE \\ DEGREE OF MASTER OF SCIENCE
}

GRADUATE PROGRAM IN NEUROSCIENCE

CALGARY, ALBERTA

JANUARY, 2019

(C) Thomas James Phillips 2019 


\begin{abstract}
Background: Postictal hypoxia (PIH) is a stroke-like event that follows seizures and may be responsible for the postictal state. PIH may also be a contributing factor to the development of seizure-induced brain abnormalities and behavioral dysfunction associated with epilepsy. Caffeine is the world's most popular drug with $\sim 85 \%$ of people in the US consuming it daily. Thus, persons with epilepsy are likely to have caffeine in their system during seizures. This preclinical study investigated the acute and chronic effects of caffeine on tissue oxygenation pre and post seizure.
\end{abstract}

Methods: We utilized the electrical kindling model in rats. A stimulating/recording electrode was placed into the rat ventral hippocampus (CA3), and an oxygen measuring optrode in dorsal hippocampus (CA1). Rats were administered vehicle (saline) or caffeine $(5.0,10.0$, or 15.0 $\mathrm{mg} / \mathrm{kg}$ ) intraperitoneally, 30 minutes prior to an elicited seizure. Hippocampal oxygen levels were continually measured post-injection, and post-seizure, until returning to the normoxic range. Further, rats were administered various agonists and antagonists to determine adenosine receptors role in PIH. Lastly, rats were administered a chronic regime of caffeine to determine the long-term effects of caffeine in relation to PIH.

Results: Caffeine at high $(15.0 \mathrm{mg} / \mathrm{kg})$ doses, caused a significant drop in pre-seizure hippocampal $\mathrm{pO}_{2}$. Following a seizure, caffeine at $10.0 \mathrm{mg} / \mathrm{kg}$ and $15.0 \mathrm{mg} / \mathrm{kg}$, increased the time below the severe hypoxic threshold (10mmHg). Caffeine's metabolites, paraxanthine, theobromine, and theophylline also increased the time below the severe hypoxic threshold. Adenosine A1 receptor agonist n6-Cyclopentyladenosine caused a significant drop in pre-seizure mean $\mathrm{pO}_{2}$ and increased the area below severe hypoxic threshold. A2A receptor antagonist $\mathrm{SCH}-$ 
58261 caused a significant drop in pre-seizure mean $\mathrm{pO}_{2}$. The $\mathrm{A} 2 \mathrm{~B}$ receptor, appeared to have no effect on hippocampal $\mathrm{pO}_{2}$ or $\mathrm{PIH}$. Chronic caffeine consumption resulted in an increase in the area below the severe hypoxic threshold on day 15 . Rats became tolerant to the drop-in preseizure $\mathrm{pO}_{2}$ via chronic consumption but became sensitized to the postictal severe hypoxia effects.

Conclusions: Caffeine exacerbates postictal hypoxia; thus, this research hopes to guide future clinical investigations into the effect of caffeine on postictal blood flow and postictal symptomology in persons with epilepsy. 


\section{Acknowledgements}

I would like to thank Dr. Cam Teskey for being a superb supervisor; Cam has offered excellent guidance over the past two years, and his advice has proven to be invaluable. Throughout my neuroscience masters, I had the privilege of working with some great people. Thank you to my incredible colleagues, with special thanks to Marshal, Roberto and Jordan for teaching me all the specialized techniques required to complete my thesis.

Finally, I would like to thank all my family and friends. I would not have been able to accomplish what I have, without you. Mum, Dad, Ryan, your encouragement means a lot. I'm truly thankful to have such a great family. I would also like to thank my girlfriend Claire; your unconditional love and support has allowed me to make it through the past two years. I am unable to name everyone, however, a lot of you have been there for me, and I thank you. Another special thanks to the three cats throughout my life, all amazing - please see the figure below.

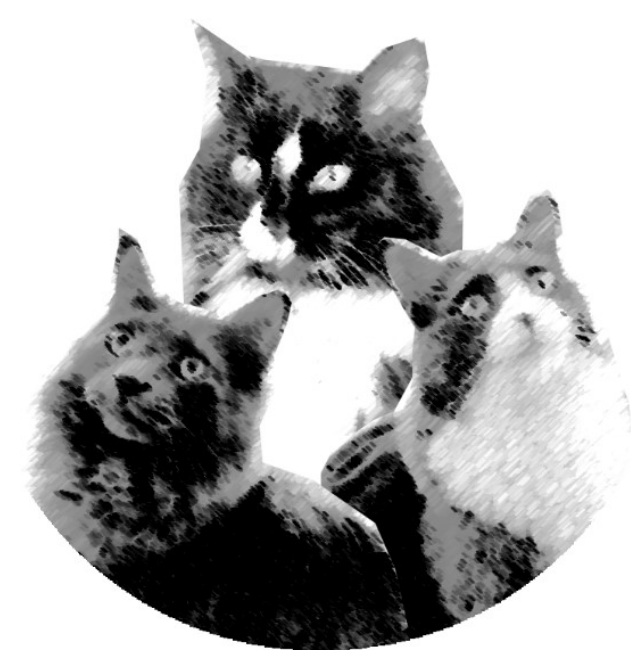

Figure: The tripartite of felines throughout my life. 


\section{Table of Contents}

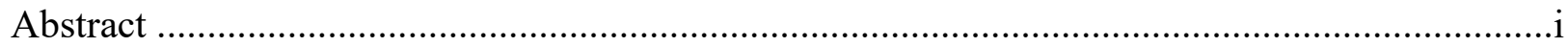

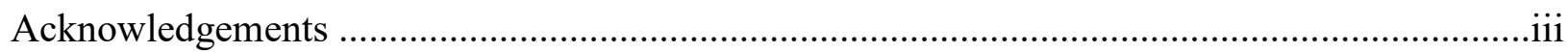

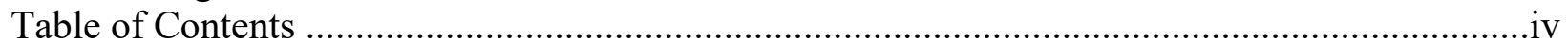

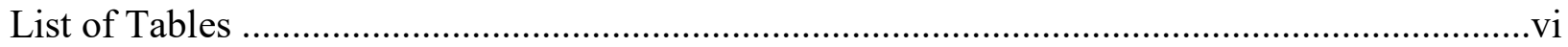

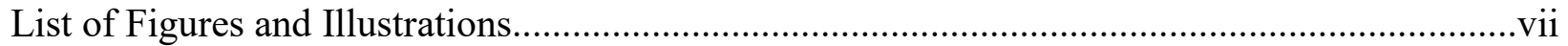

List of Symbols, Abbreviations and Nomenclature .............................................................iii

\section{Chapter One: General introduction}

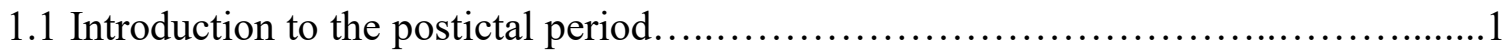

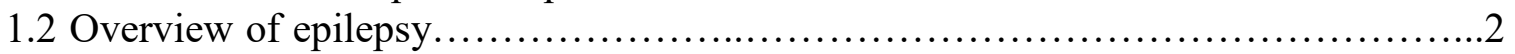

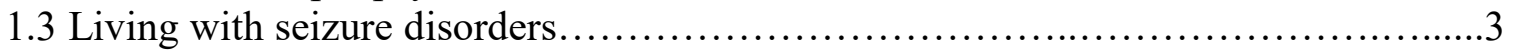

1.4 Postictal behavioural disruption..................................................

1.5 Postictal vasoconstriction leads to hypoperfusion/hypoxia ........................5

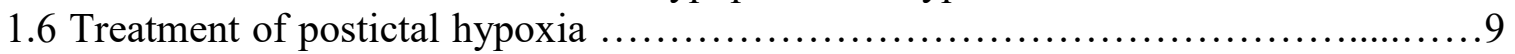

1.7 Three commonly consumed drugs and their effects on vasculature function...........12

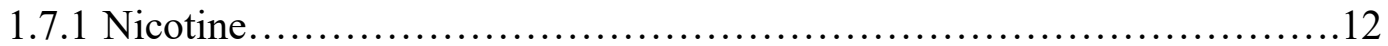

1.7.2 Ethanol ..........................................................

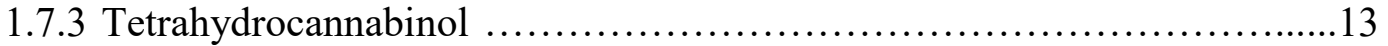

1.8 The effects of caffeine on vasculature function................................... 14

1.8.1 The metabolites of caffeine........................................... 14

1.8.2 Adenosine........................................................... 16

1.8.3 Adenosine A1 Receptors...........................................16

1.8.4 Adenosine A2 Receptors.............................................. 17

1.8.5 Adenosine A3 Receptors............................................18

1.8.6 Other targets.................................................. 18

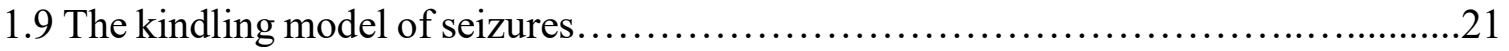

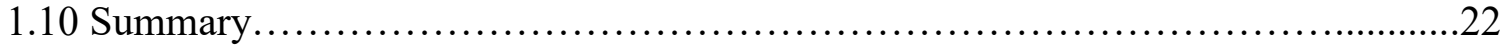

\section{Chapter Two: Caffeine Exacerbates Postictal Hypoxia}

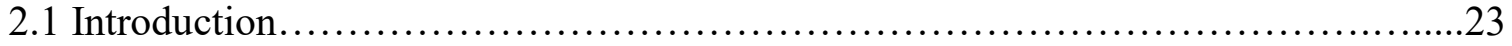

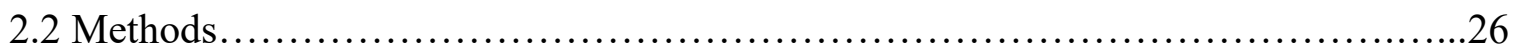

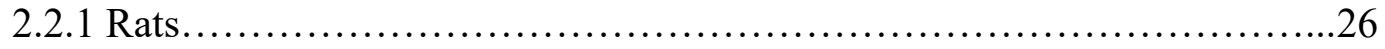

2.2.2 Electrode and optrode implantation.................................26

2.2.3 Kindling and oxygen Recording ...................................27

2.2.4 Pharmacology.................................................. 28

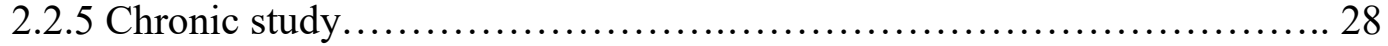

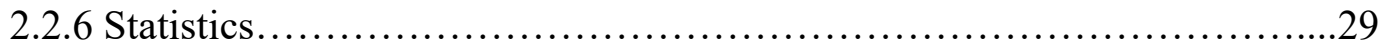

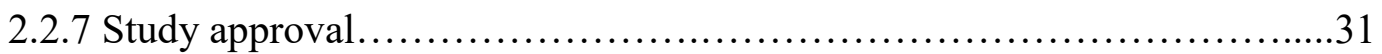

2.3 Results...................................................................

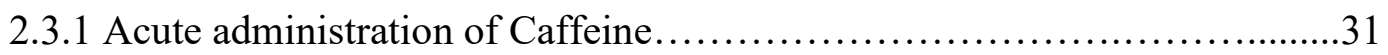

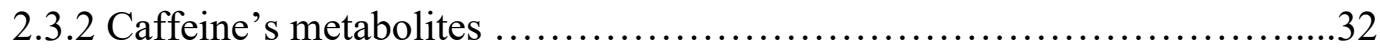

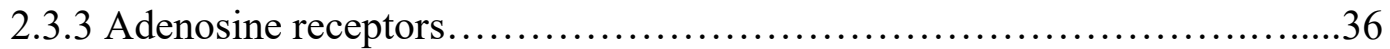

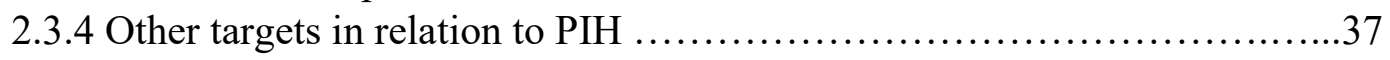


2.3.5 Chronic administration of caffeine on PIH................................ 37

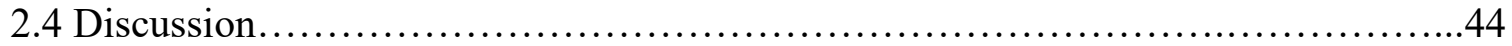

\section{Chapter Three: General Discussion}

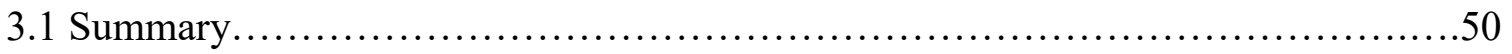

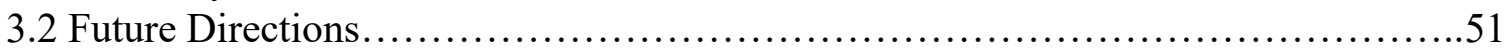

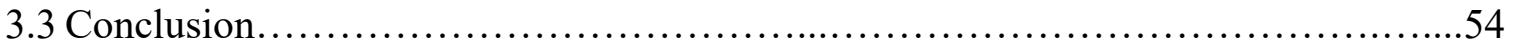

\section{Appendix: Unpublished data}

A.1 Three commonly consumed drugs: Nicotine, Ethanol and THC in relation to PIH...55

A.2 Exogenous mixture of $5 \% \mathrm{CO}_{2}, 95 \% \mathrm{O}_{2}$ fails to alleviate $\mathrm{PIH} \ldots \ldots \ldots \ldots \ldots \ldots \ldots . . . .57$

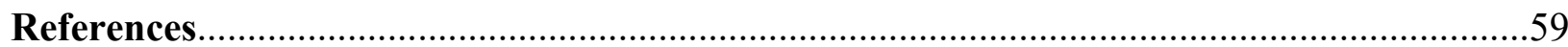




\section{List of Tables}

1.1 Adenosine Receptors and their expression........................................

2.1 Molecular targets in relation to caffeine and postictal hypoxia...........................25

2.2 Summary of the investigation into mechanisms involved in caffeine and severe postictal

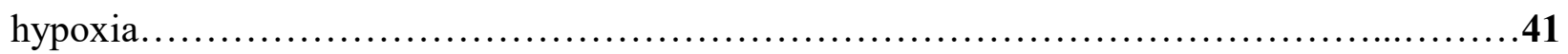




\section{List of Figures and Illustrations}

Figure 1.1 Local tissue oxygenation in the hippocampus of an awake, freely-moving rat.

Figure 1.2. Potential acute (singular) and chronic (repeated) effects of postictal

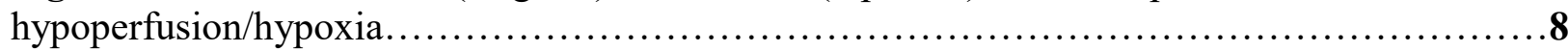

Figure 1.3 Two key molecular targets mediating postictal hypoperfusion/hypoxia.............11

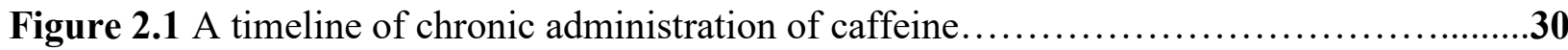

Figure 2.2: Caffeine in naïve animals causes a significant reduction

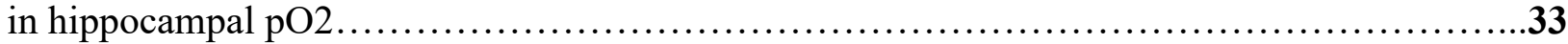

Figure 2.3: Caffeine exacerbates postictal hypoxia...................................

Figure 2.4: Caffeine's metabolites cause changes in hippocampal pO2, while prolonging the

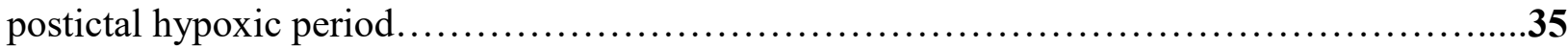

Figure 2.5: A1 receptor activation causes profound drop in hippocampal pO2 ..............38

Figure 2.6: Blocking the A2A receptor causes profound drop in hippocampal pO2............39

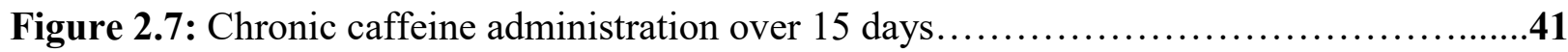

Figure 2.8: Caffeine naïve rats compared to chronic caffeine rats.....................42

Figure 2.9: Mean consumption of caffeine throughout the chronic experiment ..................43

Figure A.1: Three commonly consumed drugs: Nicotine, Ethanol and THC have no relation to PIH.........................................................................56

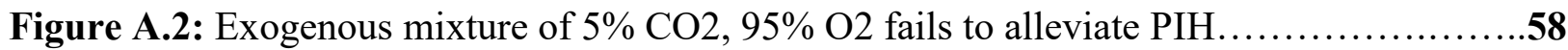




\section{List of Symbols, Abbreviations and Nomenclature}

Symbol

2-AG

AA

ADP

ADT

ASD

ATP

CAMP

CBF

CNS

COX-1

COX-2

IP3

N6

NO

PGE2

PIH

$\mathbf{p O}_{2}$

SUDEP

THC

\section{Definition}

2-Arachidonylglycerol

Arachidonic Acid

Adenosine diphosphate

After Discharge Threshold

Anti-Seizure Drugs

Adenosine Triphosphate

Cyclic Adenosine Monophosphate

Cerebral Blood Flow

Central Nervous System

Cyclooxygenase-1

Cyclooxygenase-2

Inositol triphosphate

N6-cyclopentyladenosine

Nitric oxide

Prostaglandin E2

Postictal Hypoxia

Partial Pressure of Oxygen

Sudden Unexpected Death in Epilepsy

Tetrahydrocannabinol 


\section{Chapter One: General introduction}

\subsection{Introduction}

The postictal state is largely an overlooked aspect within the epilepsy field. This state is defined by brain region specific impairments that last from minutes to days post seizure. Todd's paresis, a postictal state described over 160 years ago, defines a temporarily paralysis (or weakness) of the limbs contralateral to seizure activity (Todd, 1859). The underlying cause of postictal symptoms, including Todd's paresis and postictal amnesia, have historically not been understood, and were originally thought to be caused by neuronal exhaustion. Further, due to the unknown cause of postictal impairments, there was no clinical treatment for postictal states. Farrell et al. (2016) found that after a seizure, structures involved in the seizure activity have a local drop-in oxygen, falling below the critical severe hypoxic threshold of $\mathrm{pO}_{2}=10 \mathrm{mmHg}$ for around 60 minutes or more. This hypoxic state is caused by local vasoconstriction that is COX-2 dependant. Importantly, this vasoconstriction leads to hypoperfusion and hypoxia which temporally coincides with behavioural deficits found after seizures. Prevention of this hypoxia averts postictal symptoms. This discovery is important as it provides a viable and treatable target for postictal behavioural impairments. Indeed, the local and severe drop in oxygen may even be a physiological metric for defining the postictal state, the period of impairment after seizure.

This thesis examines how four commonly consumed drugs: ethanol, nicotine, tetrahydrocannabinol, and caffeine may alter the postictal hypoxic period. All these drugs are consumed by persons with epilepsy and each has its own effects on cerebral vasculature. By examining these four drugs effects on hippocampal oxygen levels before, during and after hippocampal seizures, we can determine their effects on the postictal state. Ultimately this thesis examines how caffeine prolongs postictal hypoxia and seeks to elucidate the molecular 
underpinnings of this effect. This thesis also examines how chronic administration of caffeine changes its effect on postictal hypoxia over time.

\subsection{Overview of Seizures and Epilepsy}

Approximately $8-10 \%$ of people will have a seizure in their lifetime (Hauser, Annegers, \& Kurland, 1993). Seizures are defined as the transient occurrences of signs and/or symptoms caused by excessive or hypersynchronous neuronal firing (Fisher et al., 2005). Seizures may be classified as either focal or generalized. Focal seizures originate when hypersynchronous neuronal activity is initiated in a single hemisphere, with a fairly consistent location of ictal onset over repeated seizures. Generalized seizures affect both hemispheres and the hypersynchronous activity originates locally before rapidly propagating into bilaterally-distributed networks (Berg et al., 2010).

Seizures may be caused by six underlying variables - genetic, structural, metabolic, immune, infectious, and unknown. Seizures can be caused by single genes that encode voltage or ligand gated ion channels. Other single-gene mutations cause alternations in neuronal maturation and migration. A combination of polymorphisms may also cause an alteration in neuronal excitability (Abad, Vilaplana, \& Fernandez, 2007). Structural abnormalities may also lead to the generation of seizures including focal cortical dysplasia, trauma, and ischemic damage. Metabolic seizures are the result of biochemical changes. Immune seizures are the result of autoimmune responses causing CNS inflammation (encephalopathy). While seizures are associated with epilepsy, the occurrence of one seizure is not a basis for epilepsy itself; a single seizure may be provoked by organ failure, reaction to pharmaceuticals, electrolyte imbalance, inflammatory response/fever, 
and drug withdrawal (Delanty, Vaughan, \& French, 1998). Seizures are required for a diagnosis of epilepsy.

Epilepsy is a neurological disorder characterized by an enduring predisposition to generate epileptic seizures (Fisher et al., 2005). This predisposition can be thought of in terms of a low seizure threshold, an imbalance between excitatory and inhibitory forces, leaving one vulnerable to epileptiform activity (electrographic seizure). Epilepsy is clinically diagnosed with the occurrence of at least one seizure with the probability of further seizures, similar to the general recurrence risk after two unprovoked seizures (Fisher et al., 2014). Epilepsy is one of the oldest known human conditions, with descriptions dating back to 2000 BC (Magiorkinis et al., 2010). Today epilepsy is the second highest ranked in terms of global burden of disease, with current estimates of 50 million individuals having epilepsy worldwide (Leonardi \& Ustun, 2002) Epilepsy is not a singular disease but a diverse family, all of which are hallmarked by an increased predisposition to seizures. Importantly, reoccurring seizures can result in substantial sensory, cognitive and motor impairments.

\subsection{Living within a Seizure Disorder}

Seizure disorders are associated with a large burden; individuals with epilepsy often report impairment in their quality of life. These impairments include social difficulties, restriction in lifestyle, and stigmatization (Hermann and Jacoby, 2009; Fiest et al., 2014). Seizure disorders can restrict one's daily life, rendering one unable to work, drive legally, or engage in physical activities such as swimming. The decreased quality of life associated with seizure disorders can also cause significant impact on psychological health. Individuals with epilepsy are more likely to report 
major depressive disorder, anxiety disorder, panic disorder, and suicidal ideation (Tellez-Zenteno et al., 2007). Physiologically adults with epilepsy show higher prevalence of cardiovascular, respiratory, and inflammatory disorders (Ward \& Schiller, 2013).

To manage seizures, persons are often prescribed antiseizure drugs (ASD); however, approximately $20-30 \%$ of these persons have refractory epilepsy (Kwan, Brodie 2000) meaning their seizures are not satisfactorily controlled with ASDs. Within epilepsy $56 \%$ of people taking ASDs report being seizure free for at least one year, $21 \%$ of these patients utilize polytherapy, or treatment involving more than one ASD (Stephen \& Bordie, 2002). ASDs, however, are associated with many negative side effects. For instance, remacemide and carbamazepine cause disruption in attention-demanding tasks, particularly those involved in motor control and performance (Wesnes et al., 2009), whereas the drug phenytoin can cause visual-guided motor, memory, and concentration deficits (Pullianien and Jokelanien, 1995). If patients continue therapy they must, unfortunately, endure many of these side effects despite the negative effects on their quality of life.

\subsection{Postictal Behavioural Disruption}

The time following seizure termination is defined as the postictal period. In the postictal state many patients experience mild to severe sensory, cognitive, or motor deficits. Complex focal seizures can be followed by confusion or even psychosis (Kanemoto et al., 2010). Memory is often impaired following a temporal lobe seizure (Helmstaedter, Elger \& Lendt 1994) with both retrograde and anterograde amnesia (Leung et al., 2000). Postictal persons often suffer profound changes to mood; with an example of postictal anxiety or depression lasting from minutes, to hours, or even in some cases days (Lopez-Gomez et al., 2008; Kanner et al., 2010). 
Postictal behavioural deficits correspond to the location of ictal event; focal seizures in visual cortex result in visual impairments, language areas in speech deficits (both comprehension and production), memory structures in amnesia, and motor areas in muscle weakness and impaired coordination (a condition known as Todd's Paresis) (Devinsky, Kelley, \& Yacubian, 1994). In the case of Todd's Paresis, the limb weakness may render a person unable to move for an extended period. Postictal symptoms were historically thought to be the result of abnormal electrical activity, often with an emphasis on neuronal exhaustion (Binder 2004). While the electrical properties of seizures are well characterized, the vascular component following seizures has not received enough attention.

\subsection{Postictal Vasoconstriction Leads to Hypoperfusion/Hypoxia}

In the typical physiological state brain function, metabolism and blood flow are closely related. Sufficient levels of oxygen are required for normal and healthy neuronal functioning. Historically studies examining blood flow during the postictal period had mixed observations, with reports of both hypoperfusion and hyperperfusion. One of the first findings by Gibb's et al., (1934) observed an increase in cerebral blood flow immediately following a seizure. Penfield noted a sharp increase in cerebral blood flow but expressed doubts that the tissues oxygen requirements were being satisfied (Penfield, 1939). Meyer and Portnoy (1959) followed with observations, finding a period of postictal "cortical anoxia" resulting from hypoperfusion. More recent findings using SPECT imaging techniques found a period of hyperperfusion lasting six hours after seizure (Lee et al., 1990). There have also been findings of hyperperfusion during ictal activity followed by a period of postictal hypoperfusion (Newton et al., 1992). The mixed findings between blood flow and the postictal state may be attributed to the variable time-points across studies, failing to define clear 
temporal relationships. Farrell et al. (2016) sought to systematically study postictal changes in brain oxygen levels following evoked seizures, establishing well defined temporal onsets, pre and post-seizures.

Farrell et al. (2016) demonstrated that brief seizures induce a local severe hypoxic event $(\mathrm{pO} 2<10 \mathrm{mmHg})$ in the brain (Figure 1.1). This event typically lasts around one hour after seizure, a phenomenon called postictal hypoxia (PIH). The severity of PIH increases as a function of seizure duration. Farrell et al. also examined PIH within clinical populations and found seizurespecific local hypoperfusion in patients with focal epilepsy. This has subsequently been examined in more detail with the original observation supported (Gaxiola-Valdezet al., 2017). These findings are significant, providing a link between two distinct neurologic subdisciplines; epilepsy and stroke. Importantly, by linking these disorders, we can better understand some of the behavioural and brain abnormalities that result from seizure disorders. A theory put forth by Farrell and colleagues (2017), postulates that postictal hypoxia contributes to both the acute and chronic brain abnormalities and behavioural dysfunction found in people with epilepsy (Figure 1.2). Treatment or attenuation of PIH may then result in less severe consequences, both acute and chronic, for persons with epilepsy. 


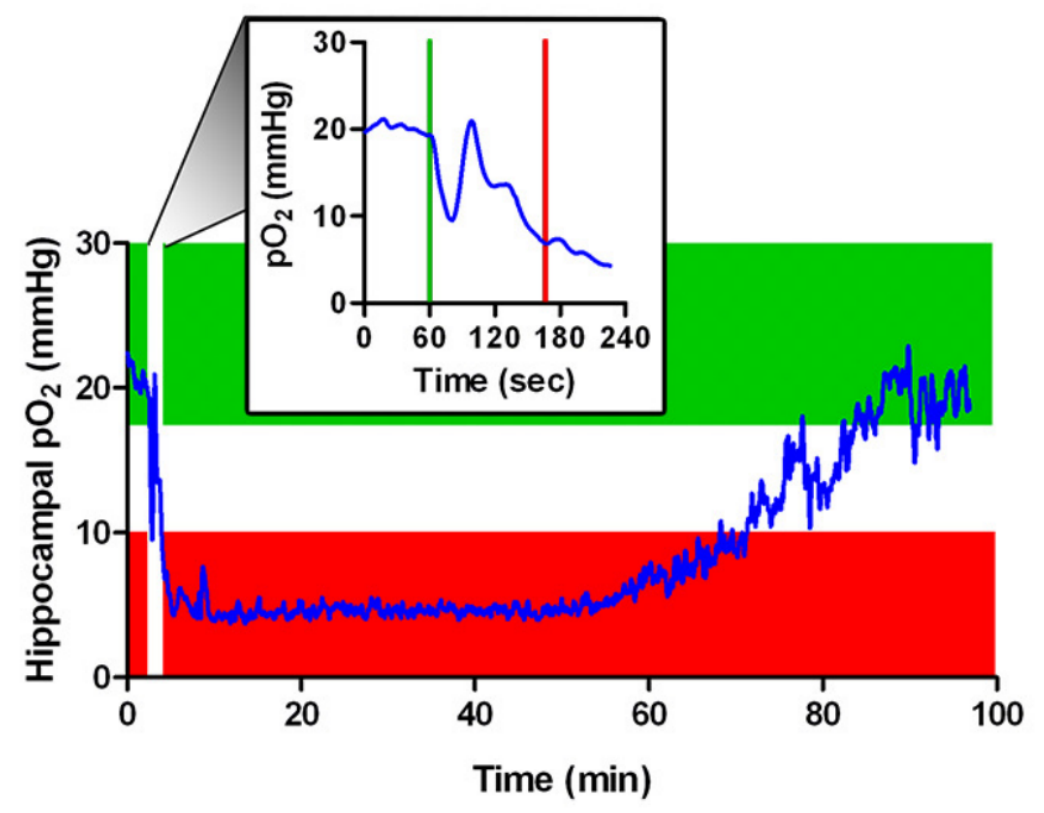

Figure 1.1 Local tissue oxygenation in the hippocampus of an awake, freely-moving rat (blue). Green denotes normoxia while red denotes severe hypoxia. Representative oxygen profile before, during, and after a $106 \mathrm{~s}$ electrically kindled seizure. Inset represents the oxygenation during the ictal event initiated at the vertical green line and terminated at the vertical red line. Taken from Farrell et al., 2016. 


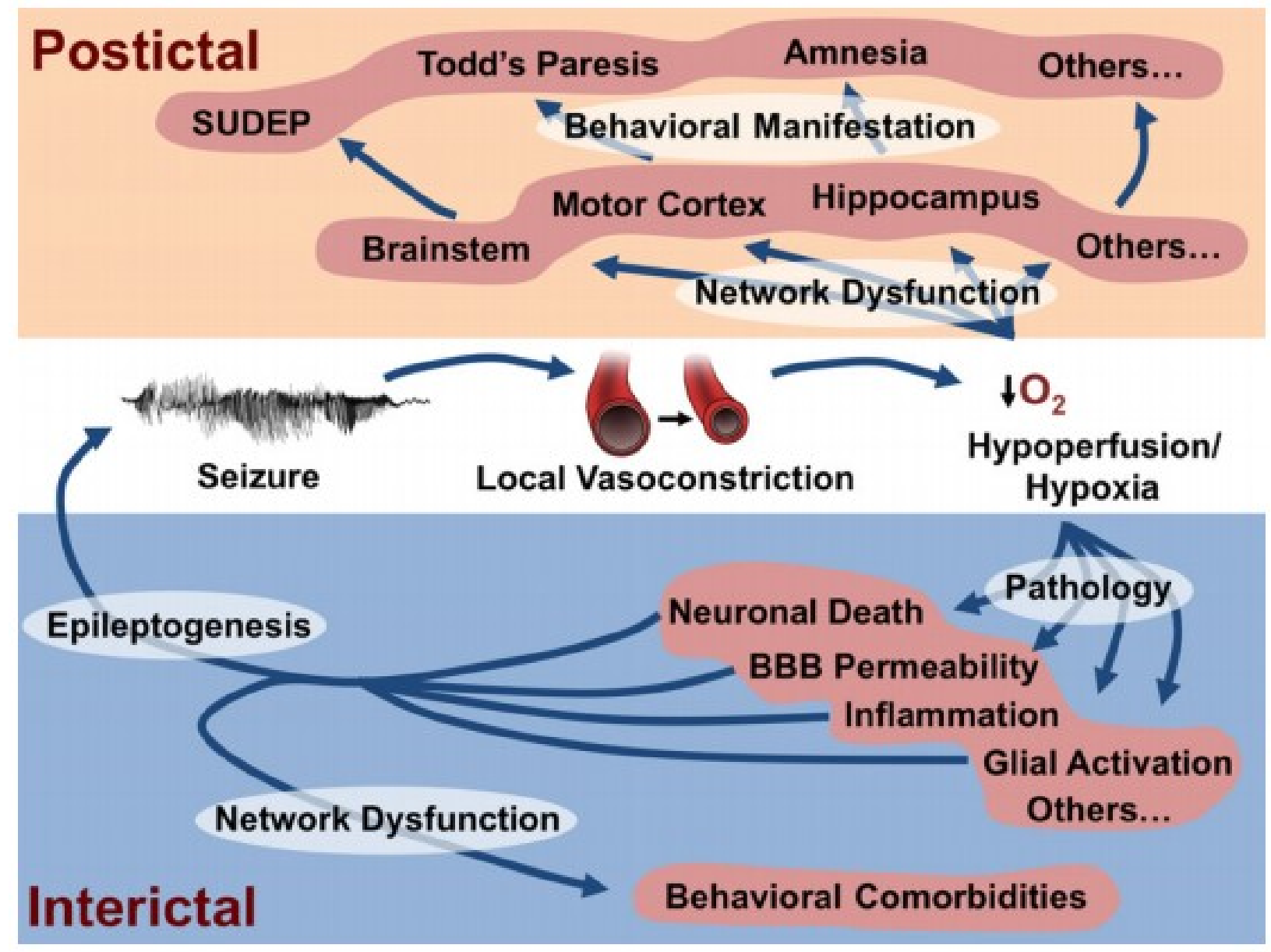

Figure 1.2. Potential acute (singular) and chronic (repeated) effects of postictal hypoperfusion/hypoxia. Hypoperfusion/hypoxia in the postictal period could impair proper local network function and result in specific behavioral impairments. Repeated episodes of postictal hypoperfusion/hypoxia may damage the brain and may also underlie interictal behavioral comorbidities. Moreover any progressive enhancement of seizure severity and/ or seizure frequency (epileptogenesis) may also be causally related to repeated episodes of postictal hypoperfusion/hypoxia. Taken from Farrell et al. 2017. 


\subsection{Treatment of Postictal Hypoxia}

Hypoxia can result in profound effects to brain structure and function (Gale \& Hopkins, 2004; van den Brink et al., 2000; Jiang et al., 1996). It is then reasonable to assume PIH also could causes potential pathophysiological and behavioural consequences, both acute and chronic, found within seizure disorders (Farrell et al., 2017). To treat PIH, two successful key targets have been identified, cyclooxygenase-2 (COX-2) and L-type calcium channels. These two targets are key to preventing the profound vasoconstriction that occurs postictally (Farrell et al., 2016) (Figure 1.3).

COX-2 is a postsynaptic enzyme that catalyzes the first step in generating the vasoactive prostanoids (prostaglandin-D2, -E2, -F2a, prostacyclin and thromboxane) from arachidonic acid (Hla \& Neilson, 1992). Vasoactive prostanoids are quickly released into the extracellular space and exert effects through G-protein coupled receptors located on vascular smooth muscle, modulating vessel diameter. Downstream of COX-2, another key target for PIH is the L-type calcium channels, located on the smooth muscle coating the arterioles. During a seizure, the activity of COX-2 is thought to be substantially increased by sustained synaptic activity. COX-2 then rapidly oxygenates substrates to vasoactive products. These vasoactive products then move out into the extracellular space, acting on yet to be identified receptors located on vascular smooth muscle. Ultimately, these receptors open L-type calcium channels, allowing extracellular calcium into the smooth muscle which engages the molecular machinery that mediates vasoconstriction. In support of this finding, $\mathrm{PIH}$ has been blocked by pre-seizure administration of COX-2 blockers and L-type calcium channel antagonists. COX-2 inhibitors must be administered pre-seizure to alleviate PIH, unlike L-type calcium channel blockers that can be administered pre- or immediately post-seizure. Importantly, while persons with epilepsy are being treated for seizures with ASD, those persons with seizures are not being treated for PIH. ASDs fail to alleviate PIH except for a 
high dosage of ethosuximide, often used to treat absence seizures, due to its effect on T-type calcium channels (Farrell et al., 2016).

Treatment of PIH can result in the attenuation of various local postictal symptoms such as Todd's paresis and memory deficits in animals. In a rat kindling model, forelimb weakness after motor cortex seizures, as measured by duration on the hanging bar task, was prevented when rats were treated with the L-type calcium channel inhibitor nifedipine (Farrell et al., 2016). Similarly, rats with hippocampal seizures had typical memory encoding in the novel object task after being pretreated with a COX antagonist (acetaminophen) whereas untreated rats failed to spend proportionally less time investigating the novel object (Farrell et al., 2016). These results suggest the acute behavioural dysfunctions are caused by the local hypoxia event, as opposed to the seizure itself. PIH then establishes itself as a valid target to improving the quality of life of persons with epilepsy. However, as PIH is yet to be treated in a clinical setting it is important to investigate other factors that may modulate the PIH response. 


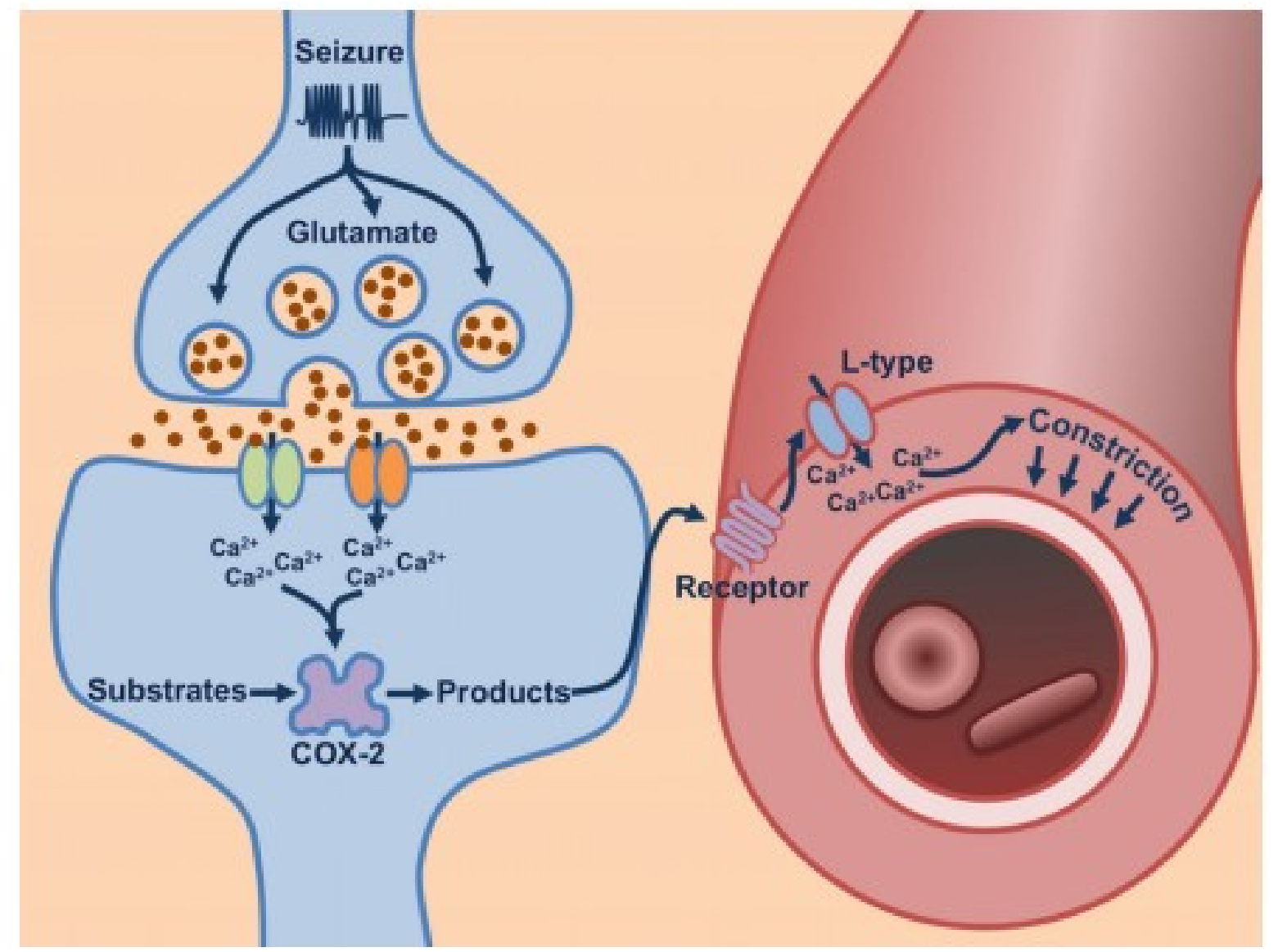

Figure 1.3. Two key molecular targets mediating postictal hypoperfusion/hypoxia. An excitatory synapse is shown in proximity to a local arteriole. Following sustained synaptic activity during a seizure, postsynaptic calcium accumulates and increases the activity of COX-2, which enzymatically converts its substrates to lipid-signaling molecules, (one such identified molecule is PGE2). These lipid-signaling molecules or more of these products act on receptor(s) located on vascular smooth muscle opening L-type calcium channels, which leads to vasoconstriction. Taken from Farrell et al., 2017. 


\subsection{Four Commonly Consumed Drugs and Their Effects on Vasculature Function}

A plethora of pharmaceuticals are known to affect vascular function under typical physiological conditions. The most popular recreationally consumed drugs: nicotine, ethanol, tetrahydrocannabinol, and caffeine also have various effects on vascular function. People with epilepsy are regular consumers of these drugs, making it likely these drugs will be in a person's system during and after a seizure.

\subsubsection{Nicotine}

Nicotine is consumed daily by $20 \%$ of the global population, primarily through the inhalation of cigarettes (WHO, 2008). Cigarette smoke is well established with an increased risk of cardiovascular dysfunction including hypertension, myocardial infarction, and stroke (Ambrose \& Barua 2004). However, as cigarettes contain greater than 7000 constituents it is difficult to establish exact molecular mechanisms, leaving the door open for other pharmacological effects other than nicotine. Nicotine is a potent parasympathomimetic stimulant, best known as an agonist at nicotinic acetylcholine receptors (Sydor \& Brown, 2009). In humans the maximum plasmic concentration is roughly 15 minutes after smoking, with a half-life of 1 to 2 hours (Mendelson et al., 2005). Nicotine can abolish or prevent the vasoconstrictive effects of Prostaglandin E2 (PGE2) (Sastry, Hemontolor, \& Olenick 1999). When blocking PGE2 with antagonist CAY-10526, there was alleviation of postictal hypoxia (Farrell et al., 2016). 


\subsubsection{Ethanol}

Ethanol is consumed on a regular basis (once a week) by around $60 \%$ of the population (Gunzerath, Faden, Zakhari, \& Warren 2004). Chronic ethanol use in the form of alcoholism affects 8.1 million or $7 \%$ of the adult American population. Ethanol is known as a psychoactive substance, acting as a GABA agonist and disrupting membrane fluidity affecting many neurotransmitters (Deitrich et al., 1989). In humans the maximum plasmic concentration is roughly 30-90 minutes after drinking, and at high concentrations has an elimination half-life of about 4-4.4 hours (Holford, 1987). Ethanol has multiple effects on vascular tissue, with contradictory findings of both vasoconstriction and vasodilation. Vasoconstriction has been demonstrated with acute ethanol administration in ethanol naïve animals (Gordon et al., 1995). Inhibition of NO pathwaysby ethanol can cause vasoconstriction (Kudo, Yuui, Kasuda, \& Hatake, 2015). Ethanol can also interfere with the translocation of $\mathrm{Ca}^{2+}$ across vascular membranes and depress contractile responses in vascular smooth muscle (Altura, Altura 1982). Ethanol has also been demonstrated to alter cellular channel permeability, resulting in vasodilation (Guivernau et al., 1987) (Malpas et al., 1990). There is also evidence that ethanol's metabolites could cause vascular effects. Acetaldehyde for example has been shown to cause smooth muscle relaxation (Mathew \& Wilson, 1986).

\subsubsection{Tetrahydrocannabinol}

Cannabis is reported to be consumed by $12 \%$ of individuals over the age of twelve (Volkow et al., 2014). THC the main psychoactive ingredient of cannabis, is a phytocannabinoid that acts as a low-affinity CB1 and CB2 receptor agonist and can induce local vasodilation (Pacher et al., 2005.). 
In humans the maximum plasmic concentration of THC is roughly 3-10 minutes after inhalation, with a half-life ranging from 20-30 hours (Grotenhermen, 2003). THC has also been demonstrated to cause reduction in vasoconstriction in the hindlimb of cats (Graham \& $\mathrm{Li}, 1973$ ).

\subsection{The Effects of Caffeine on Vasculature Function}

Caffeine is the most widely consumed drug in the world, with $85 \%$ of the US population consuming caffeine in some form or another daily (Mitchell et al., 2014). Typically, caffeine contents in a cup of coffee range from 50 to $300 \mathrm{mg}$. Caffeine is $100 \%$ bioavailable, being rapidly absorbed from the intestinal tract (Muqaku et al., 2015). In humans the maximum plasmic concentration is 30-40 minutes, with an average half-life of 2.5-4.5 hours (Echeverri et al., 2010). Caffeine is a stimulant, a methylxanthine, and is an antagonist to adenosine receptors (Poleszak et al., 2016). In smooth muscle, caffeine can inhibit phosphodiesterase, increasing levels of cyclic adenosine monophosphate (cAMP), causing vasodilation. Alternatively, when caffeine blocks adenosine receptors in smooth muscle it can also cause vasoconstriction (Echeverri et al., 2010). Caffeine has been observed to produce a $\sim 30 \%$ decrease in whole brain CBF (Cameron, Modell, Hariharan 1990). Caffeine has been shown to increase outputs of PGE2, an important lipid signaling molecule, and an abundant COX-2 product in the PIH model (Klein, Shephard, Kleinert

\& Kömhoff 2002; Ukena, Schudt \& Sybrecht, 1993). Caffeine is metabolized into three major metabolites; paraxanthine, theobromine, theophylline, which also have an affect on vasculature. 


\subsubsection{The Metabolites of Caffeine}

The most common caffeine metabolite is paraxanthine, making up approximately $84 \%$ of demethylated caffeine. Paraxanthine is a CNS stimulant, with a potency roughly equal to caffeine itself, being a nonselective adenosine receptor antagonist. Paraxanthine has a half-life of 3.1 hours. Paraxanthine differs from caffeine by acting as an enzymatic effector of $\mathrm{Na}+\mathrm{KA}+\mathrm{ATPase}$, increasing transport of potassium ions and calcium concentrations in skeletal muscle (Hawke, Allen \& Lindiger, 2000). Paraxanthine may also increase intracellular levels of calcium in smooth muscle. Like caffeine, paraxanthine can raise intracellular levels of cAMP, and increase PGE2 expression (Osswald \& Schnermann 2011).

Theobromine accounts for approximately $12 \%$ of the metabolic yield of caffeine. Theobromine is found in elevated concentrations in cocoa, a well-known ingredient in chocolate. Theobromine is a methylxanthine with similar but less potent actions as caffeine. In fact, caffeine binds to adenosine receptors with an estimated affinity two to three times greater than theobromine (Daly, Butts-Lamb, Padgett, 1983). The half-life of theobromine is around 2-3 hours.

Theophyline accounts for only $4 \%$ of caffeine's metabolite products. Theophyline has a half-life of 3-7 hours. Theophylline is often used as a medication for respiratory diseases, relaxing bronchial smooth muscle, increasing heart rate and blood pressure. Theophyline like other methylxanthines blocks the action of adenosine receptors. Interestingly theophylline as well as caffeine have reversed the effects of ASD, leading to greater convulsions (Akula, Dhir, \& Kulkarni, 2008). Regarding PIH, theophylline has been known to stimulate production of PGE2, thought to be due to induction of COX-2 (Juergens, Degenhardt, Stöber \& Vetter 1999). All methylxanthine have the common target of antagonizing adenosine. 


\subsubsection{Adenosine}

Adenosine is a purine nucleoside involved in energy transfer. Other purines such as adenosine triphosphate (ATP), adenosine diphosphate (ADP), as well as cAMP are also crucial to biochemical processes including energy transfer. Adenosine is omnipresent, being expressed in nearly all cells and is generated in extracellular space (Zimmerman, 2000). Adenosine itself acts as a neuromodulator, believed to play an important role in sleep and supressing arousal. Adenosine has been referred to as an endogenous anticonvulsant and is released after periods of hyperexcitability including seizures (Young \& Dragunow 1994). Importantly adenosine regulates blood flow by inducing vasodilation or vasoconstriction, depending on the adenosine receptor activated. While adenosine receptors are thought to contribute to cerebral vascular resting tone, inhibiting adenosine action can lead to either an increase, decrease or no difference in vascular tone (Phillis 1992). Adenosine is known to be neuroprotective, with administration of adenosine improving damage after stroke (Rudophi, Schubert, Parkinson, Fredholm 1992). Adenosine concentrations have been demonstrated to increase under metabolically unfavorable conditions, such as tissue hypoxia (Borea et al., 2015). There are three major adenosine receptor categories, A1, A2 (Including A2A and A2B), as well as A3 receptors. As caffeine has been known to cause both vasodilation as well as vasoconstriction, understanding the location and function of the adenosine receptors is crucial to understanding caffeine's effect on cerebral blood flow and thus PIH (Summarized in table 1.1). 


\subsubsection{Adenosine A1 Receptors}

Adenosine A1 receptors are a metabotropic receptor coupled to $\mathrm{G}_{\mathrm{i} / \mathrm{o}}$ proteins. A1 receptors are found to be ubiquitous throughout the entire body. A1 receptors are expressed throughout smooth muscle, and throughout the vascular system. Activation of A1 receptors causes constriction of vascular smooth muscle (Echevveri et al., 2010). Activation of $A_{1}$ receptors leads to feedback inhibition of release of presynaptic excitatory neurotransmitters, such as glutamate, preventing excitotoxic cell death under ischemic conditions (Karnesky \& Poore 2009). For this reason, activation of central A1 receptors has been proposed as a novel target in suppressing seizure activity (Gouder, Fritschy \& Boison 2003). Chronic caffeine consumption has been shown not to affect adenosine A1 receptor density (Georgiev, Johansson, Fredholm 1993). In support of this, chronic caffeine users show a $27 \%$ reduction in CBF, suggesting a limited ability for the cerebrovascular adenosine system to compensate for user's high caffeine intake (Addicott et al., 2010).

\subsubsection{Adenosine A2 Receptors}

Adenosine $\mathrm{A} 2$ receptors, both $\mathrm{A} 2 \mathrm{~A}$ and $\mathrm{A} 2 \mathrm{~B}$ receptors, are both $\mathrm{G}_{\mathrm{s}}$-coupled receptors. These adenosine receptors have been shown to increase receptor density under hypoxic conditions (Trincavelli et al 2008). Interestingly, A2A agonists have been shown to induce an increase in COX-2 mRNA levels and synthesis of PGE2 in microglia (Fiebich et al., 1996). While A2A antagonists have enhanced COX-2 expression in cortical neurons (Minghetti et al., 2007). Knockout mice lacking the A2A receptor have less COX-2 induction than wild types (Cadieux et 
al., 2005). While A1 receptors inhibit excitatory neurons, A2A receptors have the opposite effect promoting discharge within neuronal networks (Rombo et al., 2015).

\subsubsection{Adenosine A3 Receptors}

Adenosine A3 receptors are $G$ protein-coupled receptors that couple to $\mathrm{G}_{\mathrm{i}} / \mathrm{G}_{\mathrm{q}}$ proteins. Several studies have attempted to demonstrate the effects of A3 receptors on cerebral ischemia. These studies have found conflicting results; A3 receptors were found to be protective/harmful under ischemic conditions, while being pro/anti-inflammatory in others (Borea et a. 2015). It appears the location of the system is important in determining the protective or harmful roles of A3 receptors. Interestingly, A3 receptor is the only adenosine subtype to be overexpressed in inflammatory and cancer cells (Borea et a. 2015). A3 receptors are proconvulsant in the immature brain, suggesting they may facilitate early seizure induced neuronal damage (Boison, 2008). Further A3 receptors have been reported to decrease the stability of currents generated by GABA within epileptic tissue, serving as a possible therapeutic target (Roseti et al., 2009). The A3 receptors, like other adenosine receptors are thought to play a role in modulation of blood vessel function; activation of A3 receptors causes contraction through COX-1 (Ansari, Nadeem, Tilley, and Mustafa 2007.) While the main mechanism of caffeine is through antagonizing adenosine, it also exerts other effects on vasculature targets.

\subsubsection{Other targets}

Caffeine is known to inhibit inositol triphosphate (IP3), which stimulates secretion of $\mathrm{Ca}^{2}+$ from the sarcoplasmic reticulum, causing vessel contraction (Echeverri et al., 2010). Interestingly, when 
2-APB an IP3 receptor antagonist was administered there was a significant reduction in PIH (Farrell et al., 2016). This reduction in PIH is thought to be due to inhibiting the increase in free calcium. Interestingly, caffeine has also been shown to induce calcium release via ryanodine receptors, causing vasoconstriction (Morio, McMurtry, 2002). In addition, caffeine has also been known to act directly on voltage-dependant $\mathrm{Ca}_{2}+$ channels, inhibiting the entrance of external $\mathrm{Ca}_{2}+$ (Echevveri et al., 2010). In conclusion, the popularity of caffeine as the worlds most commonly consumed drug, and its effects on various molecular mechanisms related to cerebral vascular tone makes it an important target in relation to PIH. To test caffeine's relation to PIH, it's important to understand how we can utilize animal models. 


\begin{tabular}{|l|l|l|}
\hline Adenosine Receptor & $\begin{array}{l}\text { Vascular action under } \\
\text { Physiological conditions }\end{array}$ & Expression in Brain \\
\hline A1 & Vasoconstriction & $\begin{array}{l}\text { High expression in cortex, } \\
\text { hippocampus, cerebellum, } \\
\text { spinal cord (Poulsen and } \\
\text { Quinn, 1998) }\end{array}$ \\
\hline A2A & Vasodilation & $\begin{array}{l}\text { High expression in olfactory } \\
\text { bulb }\end{array}$ \\
& & $\begin{array}{l}\text { Low expression in other brain } \\
\text { regions (Poulsen and Quinn, } \\
1998)\end{array}$ \\
\hline A2B & Vasodilation & $\begin{array}{l}\text { Low expression throughout } \\
\text { brain (Poulsen and Quinn, } \\
1998)\end{array}$ \\
\hline A3 & Vasodilation & $\begin{array}{l}\text { Intermediate expression in } \\
\text { cerebellum and hippocampus }\end{array}$ \\
& & $\begin{array}{l}\text { Low expression in most of } \\
\text { brain (Poulsen and Quinn, } \\
1998)\end{array}$ \\
\hline & & \\
\hline
\end{tabular}

Table 1.1 - Adenosine Receptors and their expression

A list of adenosine receptors with vascular actions and expression in the brain and vasculature. 


\subsection{The Kindling Model of Seizures}

Animal models are critical to carrying out scientific medical research. While nocturnal rodents such as rats may not be a perfect counterpart to diurnal primates such as humans, animal models have many advantages: rodents for example, are easy to store, less costly, and have well studied life cycles. The rat model can provide valuable information to answer questions regarding epilepsy, from seizure propagation to the effectiveness of ASDs before moving to a clinical trial. One of the key animal models used to understand seizures is the kindling model.

The electrical kindling model has several benefits for studying seizures, that have been previously described (McIntyre and Gilby, 2009; Teskey, 2001). In kindling, electrodes are chronically implanted into a brain structure where epileptiform discharges are elicited. The kindling technique uses spaced and repeated stimulus intensity, resulting in the kindling phenomenon; the progressive increase of epileptiform discharges and seizure behavioural severity (Racine, 1972). These seizures can be elicited 1-3 times daily with a sufficient number of stimulations (100s) resulting in self-generating seizures (Pinel, 1978). The electrical kindling model has many advantageous over other models allowing precise spatial and temporal control over seizure location and elicitation. Kindling is also associated with lower lethality compared to other seizure models (Pinel and Rovner, 1978). As PIH results after seizures, kindling allows us to observe seizure duration and termination while providing a clear relationship with the severity of hypoxia. 


\subsection{Summary}

Epilepsy is more than just a disorder of seizures, often resulting in co-morbid conditions and a decreased quality of life. The postictal period has historically been largely an overlooked aspect within epilepsy. Farrell et al. (2016) found that after a seizure, structures involved in the seizure activity have a local drop-in oxygen, falling below the severe critical threshold for around 60 minutes or more, an event called postictal hypoxia. This period of hypoxia is caused by local vasoconstriction, that is $\mathrm{COX}-2$ dependant. $\mathrm{PIH}$ is stipulated to contribute to the development of seizure-induced brain abnormalities and behavioral dysfunction associated with epilepsy (Farrell et al., 2017). while pharmacological agents can block or attenuate PIH, such as acetaminophen or nifedipine, it has yet to be treated in a clinical setting.

While I examined three other commonly consumed drugs: nicotine, ethanol, and THC (see appendix A1) this thesis ultimately examines how the worlds most commonly consumed drug, caffeine, may contribute to the postictal period. We hypothesize that caffeine will worsen the postictal period, due to it's known action of vasoconstriction. This hypothesis is developed into three general aims:

AIM 1: Characterize acute caffeine administration on the onset and recovery of PIH.

AIM 2: Use specific agonists and antagonists to determine how caffeine exerts such effects, elucidating the common molecular machinery involved in PIH.

AIM 3: Characterize the chronic use of caffeine on the onset and recovery of PIH.

Ultimately, this thesis seeks to guide future research and determine if caffeine is safe to be consumed by persons with self generating seizures. 


\section{Chapter Two: Caffeine Exacerbates Postictal Hypoxia}

\subsection{Introduction:}

The postictal state is largely an overlooked aspect of epilepsy (Khan et al., 2018; Subota et al., 2018) that is defined by brain region specific impairments, ranging from amnesia to weakness (MacEachern et al., 2017), results in reduced quality of life (Josephson et al., 2016) and is currently untreated. Local arterioles in those areas of the brain involved in seizure activity become constricted leading to hypoperfusion (Farrell et al., 2016; Gaxiola-Valdez et al., 2017) and have oxygen levels, fall from the normoxic range $\left(\mathrm{pO}_{2}=18-30 \mathrm{mmHg}\right)$ to below the critical severe hypoxic threshold of $\left(\mathrm{pO}_{2}=10 \mathrm{mmHg}\right)$ for more than an hour (Farrell et al., 2016). Brain oxygen levels below the severe hypoxic threshold have independently been demonstrated to cause significant changes to cellular physiology (Farrar, 1991) and a predictor of brain injury severity (van den Brink et al., 2000; Maloney-Wilensky et al., 2009). The postictal severe hypoxic state can be prevented by pre-treatment with either cyclooxygenase-2 (COX-2) blockers and L-type calcium channel antagonists (Farrell et al., 2016). Importantly, this hypoxic event coincides with behavioural deficits found after seizures. Further, PIH is suggested to contribute to network dysfunction, contributing to both acute and chronic conditions found within epilepsy (Farrell et al., 2017).

Caffeine is the most widely consumed drug in the world, with $85 \%$ of the US population consuming caffeine in some form or another daily (Mitchell et al., 2014). Caffeine is found within a variety of drinks, foods, and some medications. Typically, the caffeine content in a cup of coffee range from 50 to $300 \mathrm{mg}$ and may range from $50 \mathrm{mg}$ to $505 \mathrm{mg}$ per energy drink (Reissig, Strain \& Griffiths, 2009). Caffeine is 100\% bioavailable, being rapidly absorbed from the intestinal tract (Teekachunhatean et al., 2013). In humans the maximum plasmic 
concentration is 30-40 minutes, with an average half-life of 2.5-4.5 hours (Echeverri et al., 2010). Caffeine is a stimulant, a methylxanthine, and an antagonist to adenosine receptors (Daly, 1982). Caffeine has been known to produce both vasodilation and vasoconstriction. In smooth muscle, caffeine can inhibit phosphodiesterase, increasing levels of cAMP, causing vasodilation. Alternatively, when caffeine blocks adenosine receptors, A2A and A2B, in smooth muscle cells it can also cause vasoconstriction (Echeverri et al., 2010). Caffeine has been shown to increase PGE2, an important lipid signaling molecule, and an abundant cyclooxygenase-2 (COX-2) product (Ukena, Schudt \& Sybrecht, 1993). Caffeine has various vascular targets that may interact with PIH, some of which have been investigated by Farrell et al., 2016, and so will not be investigated in this study (Table 2.1).

Due to the popularity of caffeine, we sought to investigate the effect of caffeine on postictal severe hypoxia. Given caffeine's known vasoconstrictive mechanisms of action (Nehlig, 1999) we hypothesized that it would worsen the PIH profile. We first determined the acute effect of caffeine on local hippocampal oxygen levels and then its effect following a seizure. We then examined the effects of caffeine's three major metabolites, paraxanthine, theobromine and theophylline on PIH. Further, the contribution of specific adenosine receptors was probed with a series of agonist and antagonist at different receptors. Lastly, we examined chronic administration of caffeine, as most persons consume caffeine regularly, in relation to PIH. 


\begin{tabular}{|l|l|l|}
\hline Target & Relation to Caffeine & Knowledge in relation to PIH \\
\hline A1 Receptor & Antagonised & N/A \\
\hline A2A Receptor & Antagonised & N/A \\
\hline A2B Receptor & Antagonised & N/A \\
\hline Paraxanthine & Major metabolite & N/A \\
\hline Theobromine & Intermediate metabolite & N/A \\
\hline Theophylline & Minor metabolite & N/A \\
\hline $\begin{array}{l}\text { Voltage-dependant Ca2+ } \\
\text { Channels }\end{array}$ & Inhibits & $\begin{array}{l}\text { L-type blockers effective at } \\
\text { alleviating PIH. }\end{array}$ \\
\hline Phosphodiesterase & Non-selective PDE inhibitor & $\begin{array}{l}\text { PDE3, and PDE5 inhibition, } \\
\text { showed no effect on PIH. }\end{array}$ \\
\hline $\begin{array}{l}\text { Inositol trisphosphate (IP3) } \\
\text { Receptor }\end{array}$ & Inhibits IP3 receptors & $\begin{array}{l}\text { IP3r Antagonist showed } \\
\text { significant reduction in PIH }\end{array}$ \\
\hline Nitric Oxide & Increases production & $\begin{array}{l}\text { NO precursor, L-arginine } \\
\text { showed no effect on PIH. }\end{array}$ \\
\hline
\end{tabular}

Table 2.1 - Molecular targets in relation to caffeine and postictal hypoxia

A list of potential molecular targets in relation to caffeine, the last four of which will not be investigated here as they have already been examined by Farrell et al. 2016 in relation to postictal hypoxia. 


\subsection{Methods:}

\subsubsection{Rats}

Young adult male hooded Long Evans (LE) rats, weighing 250-300g at the start of experiment where used in this study $(\mathrm{N}=22)$. Rats were individually housed in clear plastic cages, on a $12 \mathrm{hr}$ $: 12 \mathrm{hr}$ light/dark cycle, with lights turning on at 7:00 hours. Food and water were available ad libitum. All experiments occurred during the light phase.

\subsubsection{Electrode and optrode implantation}

A bipolar electrode was built using $178 \mu \mathrm{m}$ diameter stainless steel wire (A-M systems) capped with gold amphenol pins (CDM electronics). Rats were anesthetized with a mix of 5\% isoflurane and $100 \%$ oxygen, modulated appropriately throughout surgery via foot pinch reflex tests. Rats were placed on a heating pad to maintain a constant body temperature. Rats heads were secured in place using a stereotaxic ear bar device. Lidocaine was administered subcutaneously at the site of incision. Buprenorphine was administered IP as an analgesic. Rats were administered with baytriyl pre-operatively. Following the incision, burr holes were drilled in the skull in accordance with previously determined coordinates such that the electrode and optrode could be lowered into ventral CA3 and dorsal CA1 of the hippocampus, respectively. Electrodes and optodes were placed in accordance with bregma. Electrodes were placed, AP: -5.0mm, ML: +5.0mm, DV: -7.00mm. Optrodes were placed AP: $-3.0 \mathrm{~mm}$, ML: $+3.5 \mathrm{~mm}$, DV: $-4.0 \mathrm{~mm}$. The electrode, optrode, and ground pin were fixed to the skull using five stainless steel screws and dental cement. Post surgery each rat was provided with an appropriate dose of buprenorphine 
every 12 hours for three consecutive days. Rats received the antibiotic baytril for twice a day, totaling three days following surgery.

\subsubsection{Kindling Seizures and Oxygen Recordings}

Following a week of postsurgical recovery, each rat had an afterdischarge (AD) threshold established. A Grass S88 stimulator (Natus Neurology) delivered a 1-second train of 60-Hz biphasic rectangular wave pulses at an initial intensity of $50 \mu \mathrm{A}$, with a continued increase of 50 $\mu \mathrm{A}$ steps until an after discharge lasting 7 seconds after stimulation was elicited. The lowest intensity of stimulation required to produce an $\mathrm{AD}$ determines the animals' threshold (ADT). Stimulation is then delivered once daily at an intensity of $100 \mu \mathrm{A}$ above the ADT, ensuring a seizure was always elicited despite potential antiseizure effects of some drugs. Electroencephalogram (EEG) is recorded before and after stimulation and seizure behaviours were categorized according to the scale described by Racine (1972). Tissue oxygenation at 0.33 $\mathrm{Hz}$ (20 samples per minute) was monitored using an Oxylite Pro (Ortiz-Prado et al., 2010). As rats were kindled, they were monitored to ensure they were reliably hypoxic. As this study sought to investigate postictal hypoxia, rats who did not go hypoxic post stimulation were excluded from the study ( $\mathrm{n}=6)$. Rats who failed to go hypoxic likely did so because of a probe

placement issue, with placement in too close of proximity to a blood vessel. Rats received 10-12 kindled seizures before being used for drug experiments. After rats were connected to the fiber optic cable, they were given 5 minutes to recover from handling stress before baseline recordings were started. All recordings had 40-minute recordings of oxygen before seizure elicitation, 10 minutes of pre-injection recording, with 30 minutes post-injection, to see the effect of the drug 
on pre-seizure hippocampal oxygen. After stimulation, recordings lasted for at least 90 minutes or until the animal recovered to the normoxic range $(18 \mathrm{mmHg})$.

\subsubsection{Pharmacology}

Rats were reused for different drugs, however, for no more than 5 drug experiments. To ensure that rats PIH profiles were not permanently changed by a drug treatment, rats underwent routine vehicle recordings after each drug, these were compared to other vehicle recordings to ensure no significant differences occurred after each administration of drug. All rats were allowed at least 24 hours between drug treatments, ensuring enough clearance time for each drug, as not to interfere with other drugs administered. Rats received randomized dosages during administration for caffeine on different days. All drugs were administered IP. The following drugs, Caffeine, CSG 21680, SCH 58261, BAY 60-6583, Theophylline, Theobromine, Paraxanthine, Dantrolene, were obtained from Cayman Chemicals. Alloxazine, N6-cyclopentyladenosine (N6), DPCPX, was obtained from Sigma Aldrich. 100\% DMSO was the vehicle used for lipophilic drugs, while saline was the vehicle used for hydrophilic drugs, all drugs were injected 30 min prior to seizure induction.

\subsubsection{Chronic Study}

In a separate group $(\mathrm{n}=3)$, caffeine $1.0 \mathrm{~g} / 1$ was provided in drinking water based on methods by Yamakawa et al. (2017). The caffeine solution was changed daily at 12:00. Water consumption and rat weight were measured throughout the course of the experiment. Rats had baseline $\mathrm{pO}_{2}$ measured one day prior to chronic administration, and then on day 5,10 and 15 to measure 
caffeine's effect on pre-seizure hippocampal $\mathrm{pO}_{2}$, as well as effects on the PIH event. On the $16^{\text {th }}$ day rats received an IP injection of $15 \mathrm{mg} / \mathrm{kg}$ of caffeine, to determine the effect of chronic caffeine on PIH (Figure 2.1).

\subsubsection{Statistics}

The Statistical analysis was performed using Prism (GraphPad) version 5.01. T-tests were used for experiments with only two groups. ANOVAS were used when more than 2 groups were compared and followed up with Tukey tests to identify groups in which significant differences occurred. Repeated measure statistics were used for all within subject experiments. 


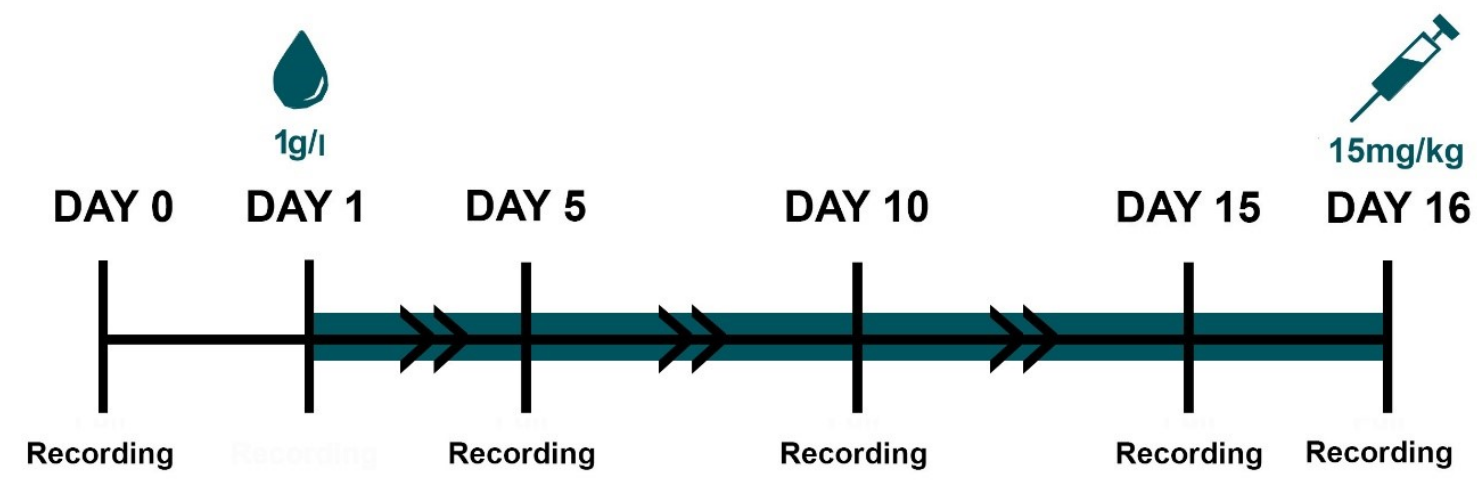

Figure 2.1 A time line of the chronic experiment: Rats established with reliable PIH profiles start the experiment on day 0 with a $\mathrm{pO}_{2}$ recording before and after a kindled seizure. On day 1 , rats received caffeine at $1 \mathrm{~g} / 1$ in their drinking water, this continued for 16 days. Every fifth day, rats received a recording, before and after seizure, to determine if chronic caffeine consumption on pre-seizure oxygen levels or PIH profiles had changed. On day 16 rats receive a $15 \mathrm{mg} / \mathrm{kg}$ IP injection of caffeine to determine the effect of chronic administration of caffeine. 


\subsubsection{Study Approval}

All animals were handled and maintained according to the Canadian Council for Animal Care guidelines. All procedures were approved by the Life and Environmental Sciences Animal Care and Health Sciences Animal Care Committees at the University of Calgary (AC16-0272). All efforts were made to adhere to the three principles of reduction, refinement and replacement (Russell and Burch, 1959), with special consideration to limit the number of subjects and minimize animal suffering.

\subsection{Results:}

\subsubsection{Acute administration of Caffeine}

Caffeine at $(10 \mathrm{mg} / \mathrm{kg})$ caused a $29.32 \%$ reduction in mean hippocampal $\mathrm{pO}_{2}$ when compared to pre-injection $\mathrm{pO}_{2}$, not returning to pre-caffeine injection for 300 minutes $(\mathrm{n}=4)$. This mean decrease did not fall below the critical threshold for hypoxia $(<10 \mathrm{mmHg})$ but was a significant $\left({ }^{*} \mathrm{p}<0.05\right)$ reduction in hippocampal $\mathrm{pO}_{2}($ Figure 2.2$)$.

Caffeine $(\mathrm{n}=5)$ at $(15.0 \mathrm{mg} / \mathrm{kg})$ significantly $\left({ }^{*} \mathrm{p}<0.05\right)$ lowered baseline $\mathrm{pO}_{2}$ before seizure administration and significantly $(* p<0.05)$ increased the area below the severe hypoxic threshold. The effect on the time below the hypoxic threshold was significant $(F(3,20)=7.48$,** $\mathrm{p}<0.01)$, a follow up independent t-test, showed $10.0 \mathrm{mg} / \mathrm{kg}(* * \mathrm{p}<0.01)$ and $15.0 \mathrm{mg} / \mathrm{kg}$ $\left({ }^{* *}<<0.01\right)$ significantly increased the time below the critical threshold for hypoxia (Figure 2.3). This data indicates that caffeine must be engaging mechanisms related to the onset or recovery of $\mathrm{PIH}$. 


\subsubsection{Caffeine's metabolites}

Caffeine produces three major metabolites, which are all non-selective adenosine receptor antagonists, and likely contribute to caffeine's long action on hippocampal $\mathrm{pO}_{2}$. We sought to investigate the metabolites themselves, to determine if they have similar effects to caffeine (Figure 4). None of the metabolites significantly ( $>0.05$ ) influenced seizure duration. Caffeine's major metabolite, paraxanthine $(1.0 \mathrm{mg} / \mathrm{kg})$ caused a significant $\left({ }^{*} \mathrm{p}<0.05\right)$ increase in the area below the critical threshold for hypoxia. Theobromine $(1.0 \mathrm{mg} / \mathrm{kg})$ had no effect on pre-seizure $\mathrm{pO}_{2}$, seizure duration or area or area below the severe critical threshold. Theophylline $(1.0 \mathrm{mg} / \mathrm{kg})$, a minor metabolite, caused a significant $\left({ }^{*} \mathrm{p}<0.05\right)$ reduction in pre-seizure mean $\mathrm{pO}_{2}$. All the metabolites caused a significant $\left({ }^{*} \mathrm{p}<0.05\right)$ increase in the time below the severe hypoxic threshold. This suggests the metabolites of caffeine are contributing the prolonged state of severe hypoxia in the hippocampus, pre and post seizure. 
A)
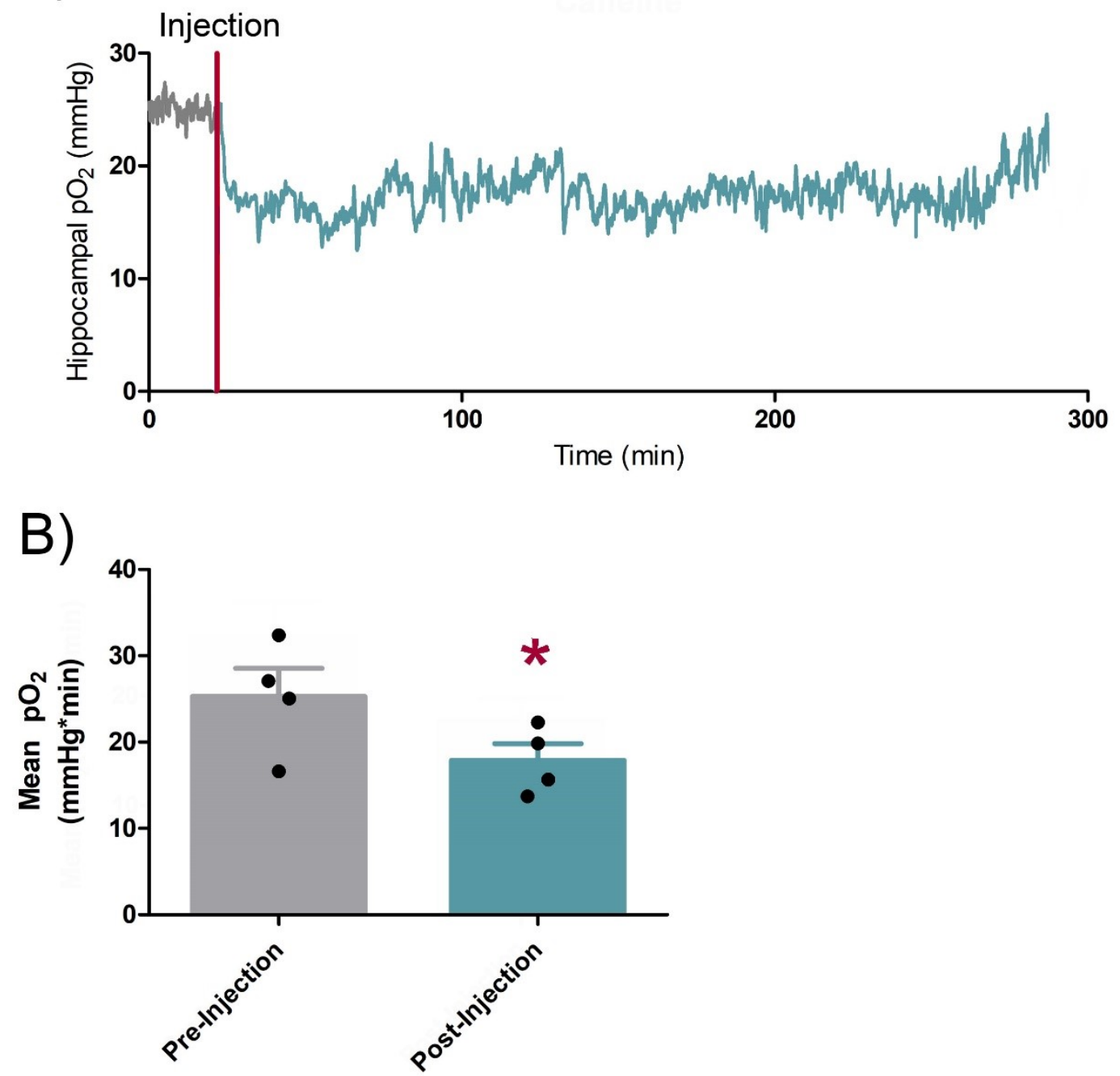

Figure 2.2: Caffeine in naïve animals causes a significant reduction in hippocampal $\mathrm{pO}_{2}$

(A) Mean $\mathrm{pO}_{2}$ line tracings displaying pre and post-injection following $10 \mathrm{mg} / \mathrm{kg}$ of caffeine, with a lasting effect of 300 minutes ( $\mathrm{n}=4$ ) (B) Quantification of (A) showing the mean 29.32\% reduction in post-injection hippocampal $\mathrm{pO}_{2}$ (over 290 minutes, until the animals returned to the normoxic range) when compared to the pre-injection hippocampal $\mathrm{pO}_{2}$ (10 minutes). This reduction was significant $* \mathrm{p}<0.05$ (paired t-test) $(\mathrm{n}=4)$. Animals were recorded until oxygen came back to pre-injection mean $\mathrm{pO}_{2}$ levels. Data displayed are means $\pm \mathrm{SEM}$. 


\section{A)}
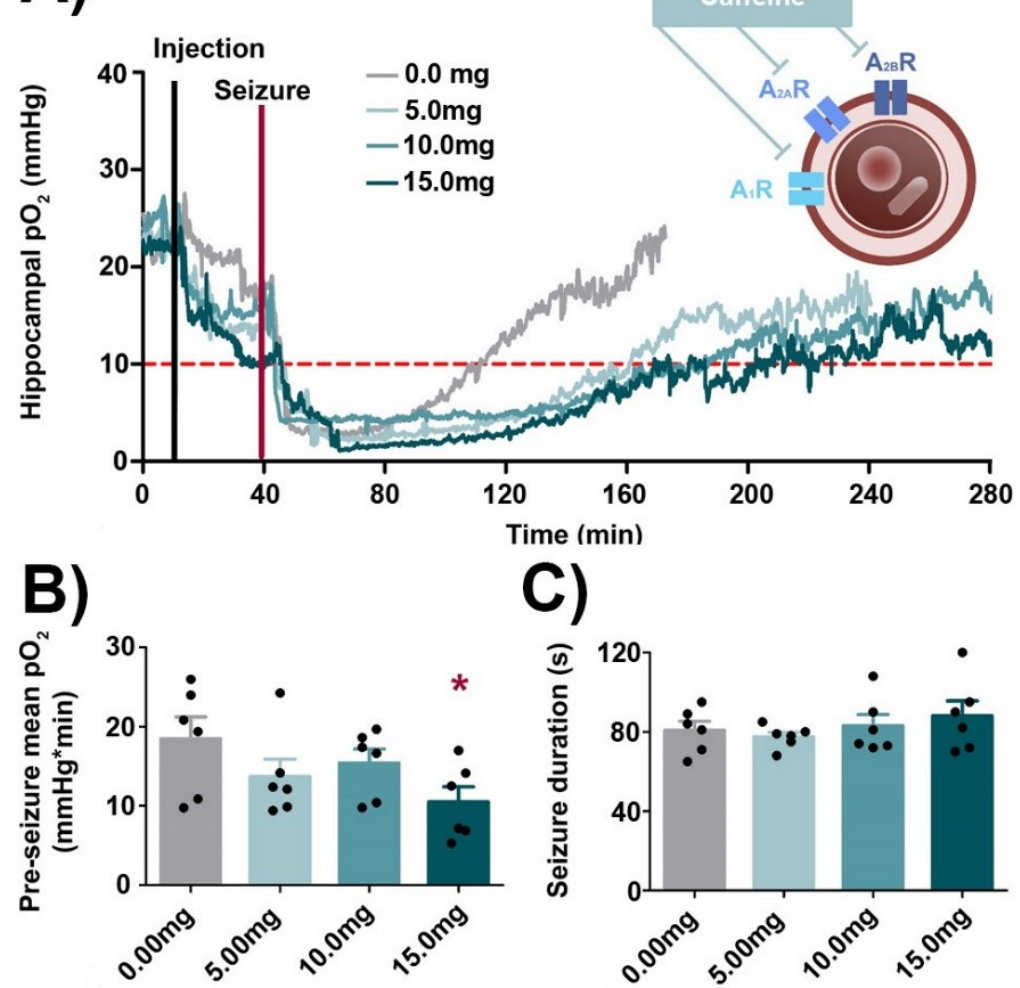

C)
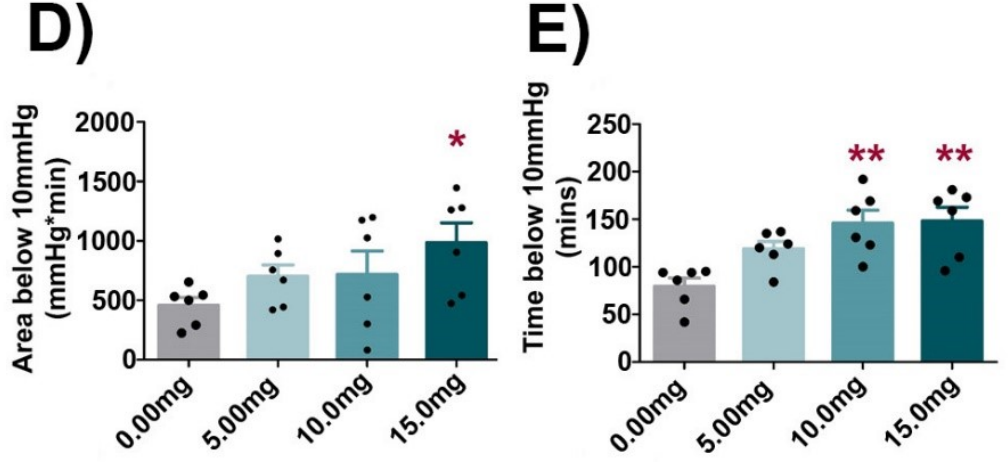

\section{Figure 2.3: Caffeine exacerbates postictal hypoxia}

(A) Mean $\mathrm{pO}_{2}$ line tracings displaying pre and post-injection of caffeine, followed by a seizure $(\mathrm{n}=6)$. Inset depicts caffeine acting on all three adenosine receptors (A1, A2A, A2B). (B) Mean $\mathrm{pO}_{2}$ ten minutes before seizure onset, $15.0 \mathrm{mg} / \mathrm{kg}$ caused a significant reduction in mean $\mathrm{pO}_{2}$ when compared to $0.00 \mathrm{mg} * \mathrm{p}<0.05$ (t-test) (C) Denotes seizure duration, no significant differences were found across dosages. (D) Quantification of (A), a significant difference was found when comparing $15.0 \mathrm{mg}$ vs $0.00 \mathrm{mg} * \mathrm{p}<0.05$ (unpaired t-test). (E) The time spent below $10 \mathrm{mmHg}$, was extremely significant $\left(\mathrm{F}(3,20)=7.48,{ }^{* *} \mathrm{p}<0.01\right.$, ANOVA). Data displayed are means \pm SEM. 

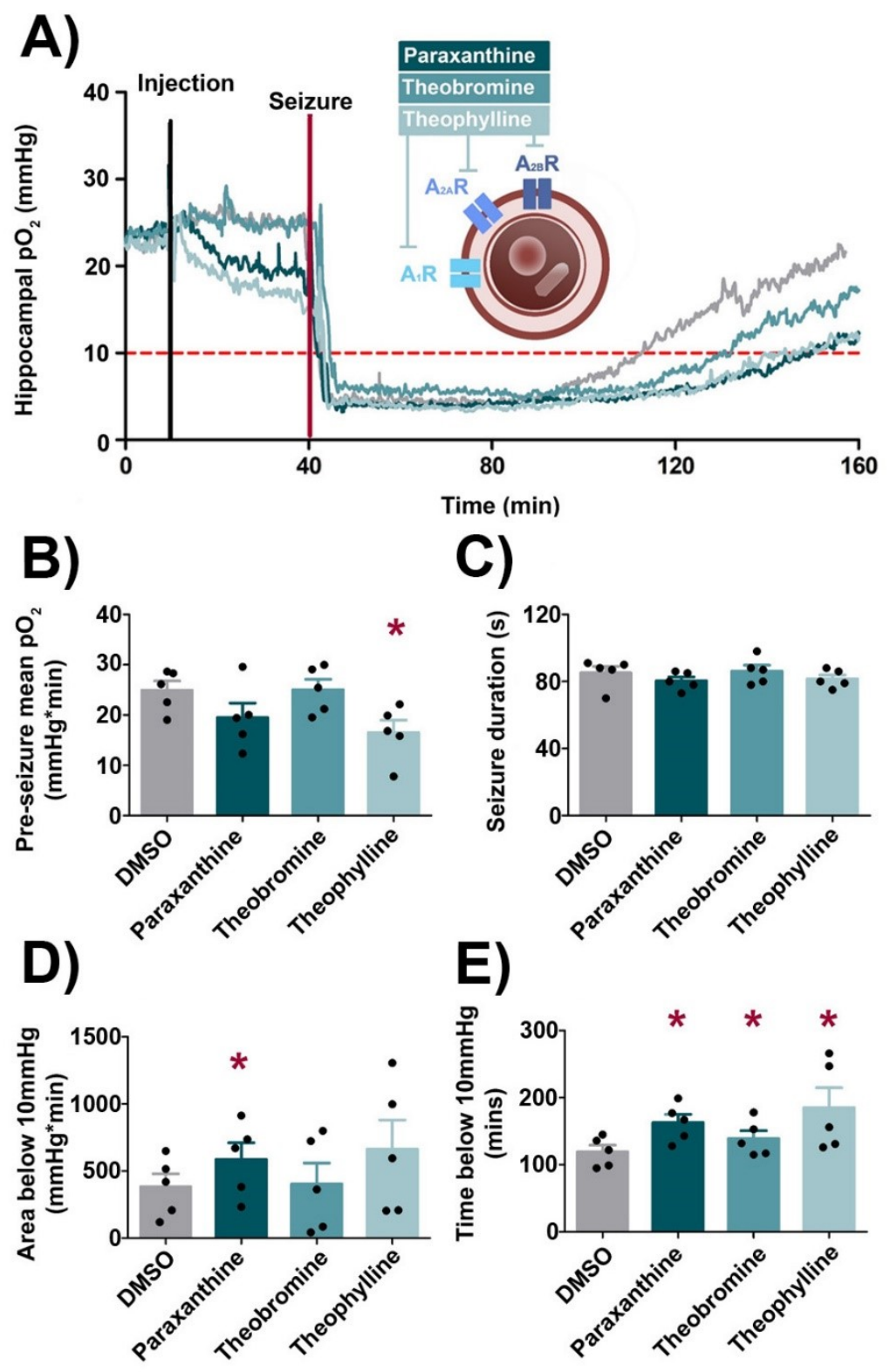

Figure 2.4: Caffeine's metabolites cause changes in hippocampal $\mathrm{pO}_{2}$, while prolonging the postictal hypoxic period

(A) Mean $\mathrm{pO}_{2}$ line tracings displaying pre and post-injection of one of the caffeine metabolites: paraxanthine $(1.0 \mathrm{mg} / \mathrm{kg})$, theobromine $(1.0 \mathrm{mg} / \mathrm{kg})$, theophylline $(1.0 \mathrm{mg} / \mathrm{kg})$, followed by seizure onset. Inset depict metabolites antagonising all three adenosine receptors. $(\mathrm{n}=5)$ (B) Mean $\mathrm{pO}_{2}$ ten minutes before seizure onset, only theophylline caused a significant reduction in mean $\mathrm{pO}_{2}$ when compared to DMSO (vehicle) ${ }^{*} \mathrm{p}<0.05$ (paired t-test) (C) Denotes seizure duration, no significant differences were found across drugs. (D) Quantification of (A), paraxanthine was caused a significant reduction in area below $10 \mathrm{mmHg} * \mathrm{p}<0.05$ (paired t-test) (E) The time spent below $10 \mathrm{mmHg}$,all three drugs increased the time below $10 \mathrm{mmHg} * \mathrm{p}<0.05$ (paired t-test). Data displayed are means \pm SEM. 


\subsubsection{Adenosine receptors}

The most established action of caffeine is its role as an adenosine receptor antagonist, thus we used specific agonist and antagonists to determine the potential contribution of each adenosine receptor (A1, A2A, A2B) to postictal hypoxia. A1 drugs had a significant effect on pre-seizure mean $\mathrm{pO}_{2}\left(\mathrm{~F}(2,3)=8.91,{ }^{*} \mathrm{p}<0.05\right)$ independent t-tests showed agonist (n6-cyclopentyladenosine) caused a significant $\left(\mathrm{p}^{*}<0.05\right)$ reduction in pre-seizure hippocampal $\mathrm{pO}_{2}$. There was a significant effect on the area below $10(\mathrm{~F}(2,3)=8.91, * \mathrm{p}<0.05)$, with a follow up t-test demonstrating N-6 significantly $\left(\mathrm{p}^{*}<0.05\right)$ increased the area below 10 (Figure 2.5$)$. A1 receptor antagonist (DPCPX) had no significant ( $\mathrm{p}>0.05$, paired t-test) effect on pre-seizure $\mathrm{pO}_{2}$, seizure duration, area or time below $10 \mathrm{mmHg}$.

Adenosine A2A receptor drugs had no effect on seizure duration ( $\mathrm{p}>0.05$, paired t-test), area below $10(\mathrm{p}>0.05$, paired t-test), or time below $10(\mathrm{p}>0.05$, paired t-test). However, there was a significant effect on pre-seizure mean $\mathrm{pO}_{2}\left(\mathrm{~F}(2,12)=8.77,{ }^{*} \mathrm{p}<0.01\right)$, a independent $\mathrm{t}$-test with $\mathrm{SCH}-58261$ showed significant $(* \mathrm{p}<0.05)$ reduction in pre-seizure hippocampal PO2 (Figure 2.6). Adenosine A2B receptor agonist (BAY 60-6583) and antagonists (alloxanzine) had no significant effect on pre-seizure mean $\mathrm{pO}_{2}(\mathrm{p}>0.05$, paired t-test $)$ seizure duration $(\mathrm{p}>0.05$, paired t-test), area ( $\mathrm{p}>0.05$, paired t-test) or time below $10 \mathrm{mmHg}(\mathrm{p}>0.05$, paired t-test $)(\mathrm{n}=5)$. This evidence supports the role of A2A for the drop in hippocampal PO2 pre-seizure elicitation, while excluding a role for $\mathrm{A} 2 \mathrm{~B}$ receptors. 


\subsubsection{Other targets in relation to PIH}

Lastly, caffeine has been shown to induce intracellular calcium release, the increase in calcium could cause contraction in smooth muscle via ryanodine receptors. We used dantrolene $(1.0 \mathrm{mg} / \mathrm{kg})$ a drug that antagonizes ryanodine receptors and thus prevents calcium release from the endoplasmic reticulum, postulated to prevent vasoconstriction. However, it showed a nonsignificant effect on pre-seizure hippocampal $\mathrm{pO}_{2}(\mathrm{p}>0.05)$, seizure duration $(\mathrm{p}>0.05)$, area $(p>0.05)$ or time below $10 \mathrm{mmHg}(p>0.05)$. Summary of the molecular targets of caffeine can be found in Table 2.3.

\subsubsection{Chronic administration of caffeine on PIH}

Rats $(n=3)$ were administered caffeine in drinking water daily. There were no significant differences in seizure duration $(\mathrm{p}>0.05)$, pre-seizure $\mathrm{pO}_{2}(\mathrm{p}>0.05)$, or area $(\mathrm{p}>0.05)$ or time ( $>0.05$ ) below $10 \mathrm{mmHg}$ for the first 10 days, on day 15 however there was a significant $\left({ }^{*} \mathrm{p}<0.05\right)$ difference in area below $10 \mathrm{mmHg}\left(\mathrm{F}(3,2)=7.65,{ }^{*} \mathrm{p}<0.05\right.$, repeated ANOVA), with a independent t-test showing a significant $(\mathrm{p}>0.05)$ increase in the area below 10 on day 15 . (Figure 2.7). Rats also failed to develop tolerance to acute injections of caffeine, with an IP injection of $15.0 \mathrm{mg} / \mathrm{kg}$ resulting in no differences in seizure duration, pre-seizure $\mathrm{pO}_{2}$ or $\mathrm{PIH}$ profiles (Figure 2.8). However, it is worth noting that rats had variable caffeine consumption throughout days $(\mathrm{F}(15,2)=9.72, * * * \mathrm{P}<0.0001$, repeated ANOVA) (Figure 2.9). This data supports the conclusion that rats may develop tolerance to the pre-seizure drop in pO2 but fail to develop tolerance to the sensitized to the effects of caffeine on PIH. 

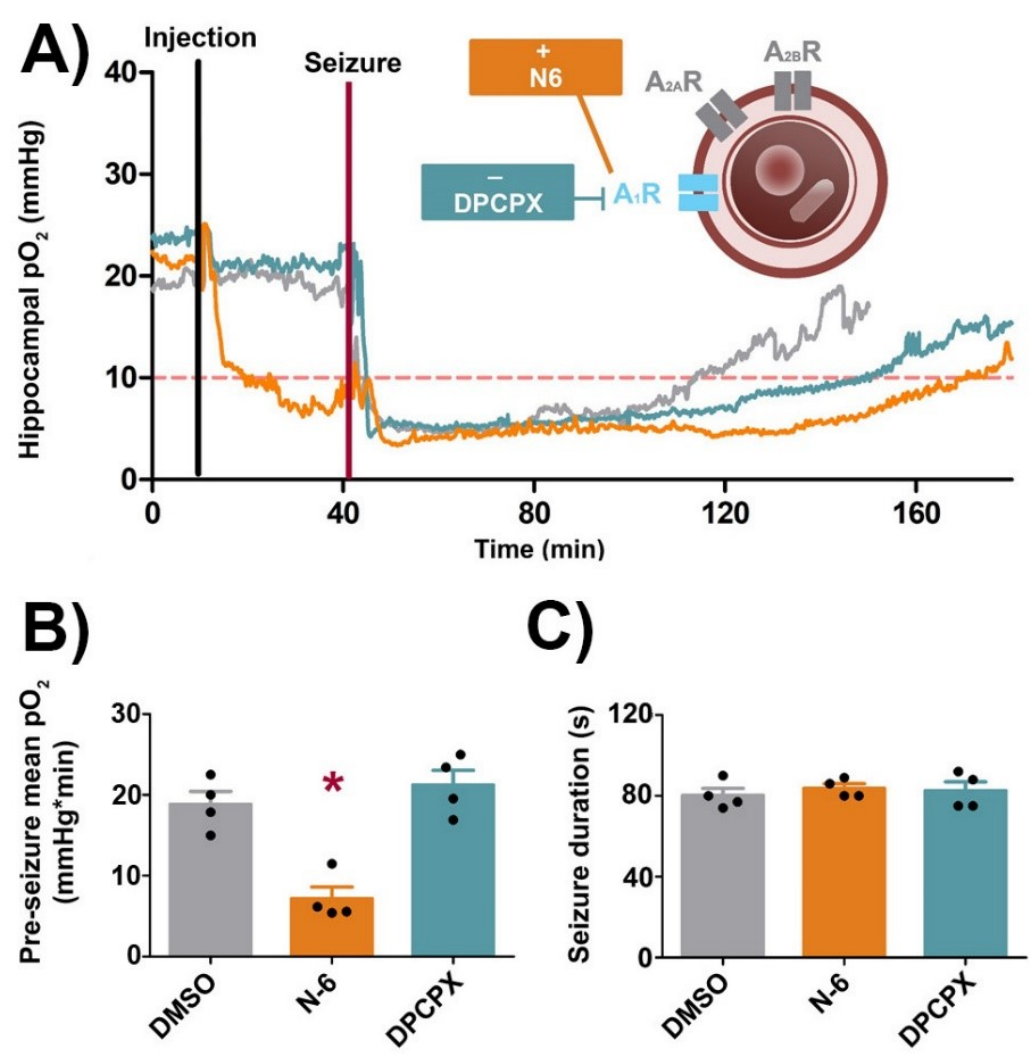

C)
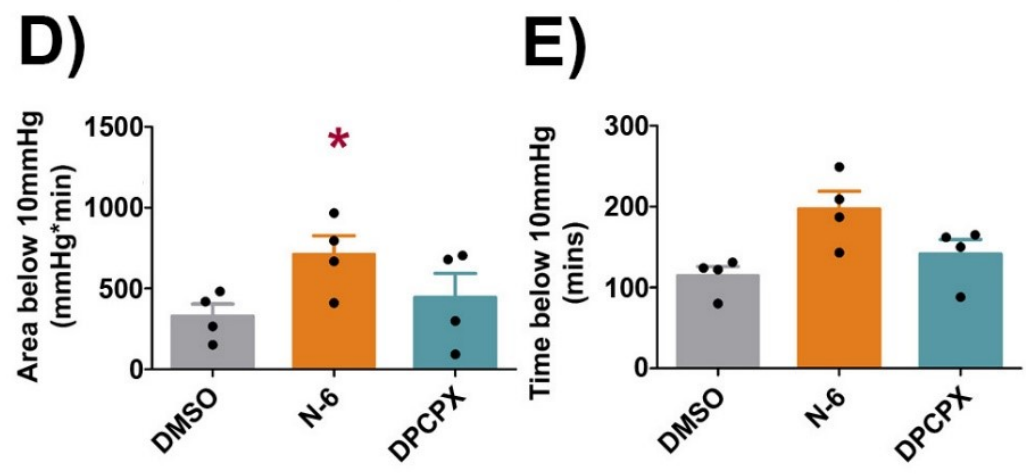

Figure 2.5: A1 receptor activation causes profound drop in hippocampal $\mathrm{pO}_{2}$

(A) Mean $\mathrm{pO}_{2}$ line tracings displaying pre and post-injection of caffeine, followed by seizure onset. Inset depict n6-Cyclopentyladenosine (N6) $(1.0 \mathrm{mg} / \mathrm{kg})$ agonizing and DPCPX antagonising A1 receptors $(1.0 \mathrm{mg} / \mathrm{kg})$. $(\mathrm{n}=4)$ (B) Mean $\mathrm{pO}_{2}$ ten minutes before seizure onset showed a significant effect $(\mathrm{F}(2,3)=8.91, * \mathrm{p}<0.05)$, N6 caused a significant reduction in mean $\mathrm{pO}_{2}$ when compared to DMSO (vehicle) $* \mathrm{p}<0.05$ (paired t-test) (C) Denotes seizure duration, no significant differences were found across drugs. (D) Quantification of (A), an effect on the area below 10 was found $\left(\mathrm{F}(2,3)=8.91,{ }^{*} \mathrm{p}<0.05\right)$, N6 increased area below $10 \mathrm{mmHg} * \mathrm{p}<0.05$ (paired t-test) (E) The time spent below $10 \mathrm{mmHg}$, no significant differences were found. Data displayed are means \pm SEM. 

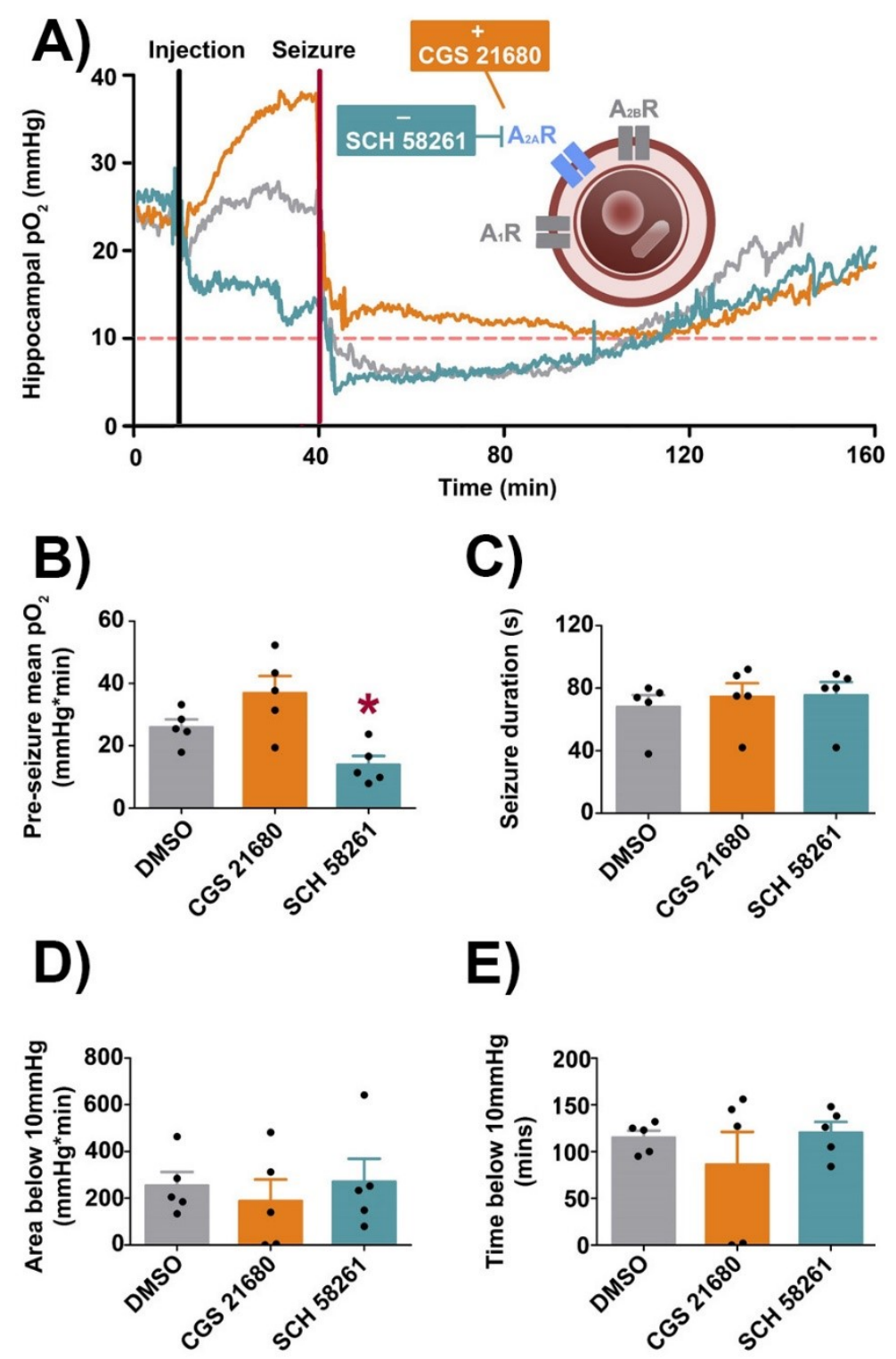

E)

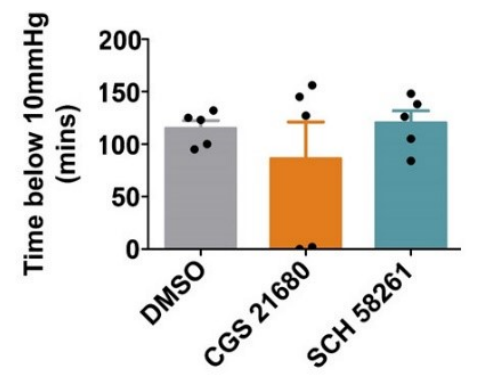

Figure 2.6: Blocking the $\mathrm{A} 2 \mathrm{~A}$ receptor causes profound drop in hippocampal $\mathrm{pO}_{2}$

(A) Mean $\mathrm{pO}_{2}$ line tracings displaying pre and post-injection of caffeine, followed by seizure onset. Inset depict CGS $21680(1.0 \mathrm{mg} / \mathrm{kg})$ agonizing and SCH-58261 (1.0mg/kg) antagonising A2A receptors. $(\mathrm{n}=5)(\mathrm{B}) \mathrm{Mean} \mathrm{pO}_{2}$ ten minutes before seizure onset, an effect of the drugs was found $(\mathrm{F}(2,12)=8.77, * * \mathrm{p}<0.01)$, SCH 58261 caused a significant reduction in mean $\mathrm{pO}_{2}$ when compared to DMSO (vehicle) ${ }^{*} \mathrm{p}<0.05$ (paired t-test) (C) Denotes seizure duration, no significant differences were found across drugs. (D) Quantification of (A), no significant difference was found (E) The time spent below 10mmHg, no significant differences were found. Data displayed are means \pm SEM. 


\begin{tabular}{|l|l|l|l|}
\hline Drug & Drug Relation & $\begin{array}{l}\text { Decrease in pre-seizure } \\
\text { hippocampal pO2 }\end{array}$ & $\begin{array}{l}\text { Increase in } \\
\text { Area below 10 }\end{array}$ \\
\hline $\begin{array}{l}\text { N6- } \\
\text { cyclopentyladenosine }\end{array}$ & A1 agonist & $\mathrm{p}=0.01(\mathrm{t}=5.94 \mathrm{df}=3)^{* *}$ & $\mathrm{p}=0.02(\mathrm{t}=4.52 \mathrm{df}=3)^{*}$ \\
\hline DPCPX & A1 antagonist & $\mathrm{p}=0.15(\mathrm{t}=1.90 \mathrm{df}=3)$ & $\mathrm{p}=0.24(\mathrm{t}=1.47 \mathrm{df}=3)$ \\
\hline CGS 21680 & A2A agonist & $\mathrm{p}=0.18(\mathrm{t}=1.64 \mathrm{df}=4)$ & $\mathrm{p}=0.21(\mathrm{t}=1.50 \mathrm{df}=4)$ \\
\hline SCH 58261 & A2A antagonist & $\mathrm{p}=0.02(\mathrm{t}=3.69 \mathrm{df}=4)^{*}$ & $\mathrm{p}=0.73(\mathrm{t}=0.37 \mathrm{df}=4)$ \\
\hline BAY 60-6583 & A2B agonist & $\mathrm{p}=0.97(\mathrm{t}=0.03 \mathrm{df}=4)$ & $\mathrm{p}=0.22(\mathrm{t}=1.44 \mathrm{df}=4)$ \\
\hline Alloxanzine & A2B antagonist & $\mathrm{p}=0.37(\mathrm{t}=0.96 \mathrm{df}=4)$ & $\mathrm{p}=0.18(\mathrm{t}=1.62 \mathrm{df}=4)$ \\
\hline Paraxanthine & $\begin{array}{l}\text { Major Caffeine } \\
\text { metabolite }\end{array}$ & $\mathrm{p}=0.13(\mathrm{t}=1.92 \mathrm{df}=4)$ & $\mathrm{p}=0.02(\mathrm{t}=3.68 \mathrm{df}=4) *$ \\
\hline Theobromine & $\begin{array}{l}\text { Intermediate Caffeine } \\
\text { Metabolite }\end{array}$ & $\mathrm{p}=0.94(\mathrm{t}=0.084 \mathrm{df}=4)$ & $\mathrm{p}=0.80(\mathrm{t}=0.27 \mathrm{df}=4)$ \\
\hline Theophylline & $\begin{array}{l}\text { Minor Caffeine } \\
\text { metabolite }\end{array}$ & $\mathrm{p}=0.03(\mathrm{t}=3.20 \mathrm{df}=4) *$ & $\mathrm{p}=0.12(\mathrm{t}=2.00 \mathrm{df}=4)$ \\
\hline Dantrolene & Inhibits CA2+ release & $\mathrm{p}=0.86(\mathrm{t}=0.18 \mathrm{df}=4)$ & $\mathrm{p}=0.18(\mathrm{t}=1.02 \mathrm{df}=4)$ \\
\hline
\end{tabular}

Table 2.3: Summary of the investigation into mechanisms involved in caffeine and severe postictal hypoxia

All drugs were delivered by intraperitoneal injection 30 minutes before seizure.

Statistics reported as different from chance (paired t-test).

$* \mathrm{p}<0.05,{ }^{* *} \mathrm{p}<0.01$ 

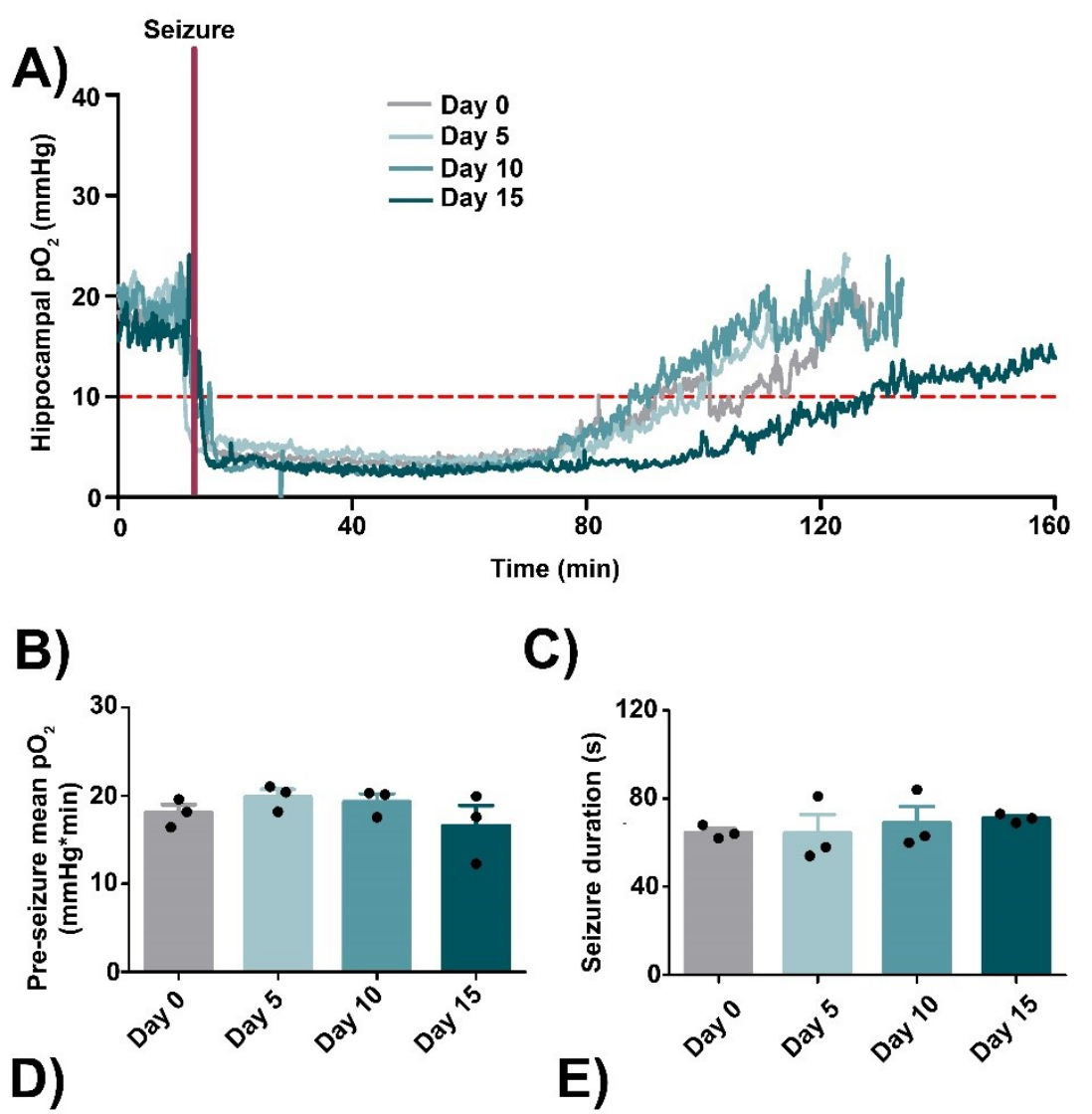

C)
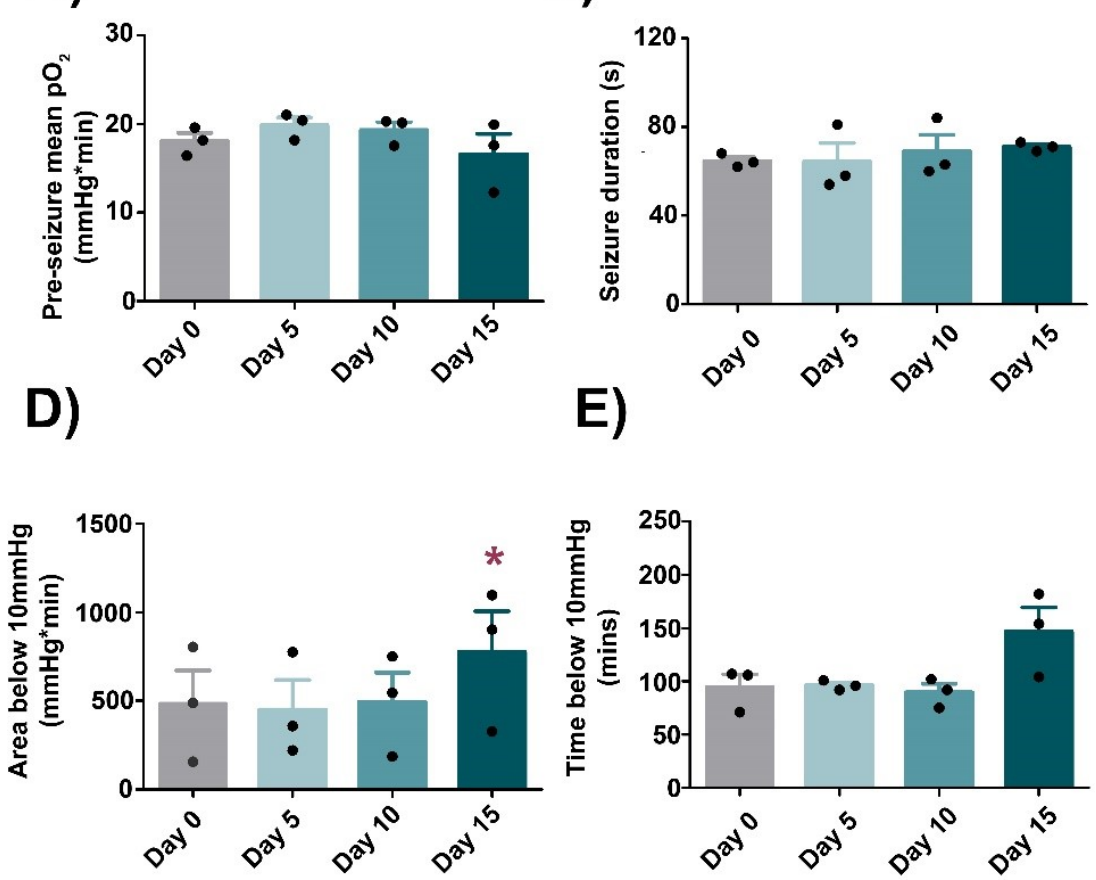

\section{Figure 2.7: Chronic caffeine administration over 15 days}

(A) Mean $\mathrm{pO}_{2}$ line tracings displaying hippocampal oxygen on different days following a chronic administration of caffeine (1g/11) followed by seizure onset. $(\mathrm{n}=3)(\mathbf{B})$ Mean $\mathrm{pO}_{2}$ before seizure onset, no significant differences were found (C) Denotes seizure duration, no significant differences were found across days. (D) Quantification of (A), repeated measures ANOVA reported a significant difference $\left(\mathrm{F}(3,2)=7.65,{ }^{*} \mathrm{p}=0.01\right)$, a paired t-test showed a significant increase in the area below $10 \mathrm{mmHg}$ on day $15\left(*^{*}<0.05\right)$ (E) The time spent below $10 \mathrm{mmHg}$, all days proved to be insignificant $(\mathrm{p}>0.05)$. Data displayed are means \pm SEM. 

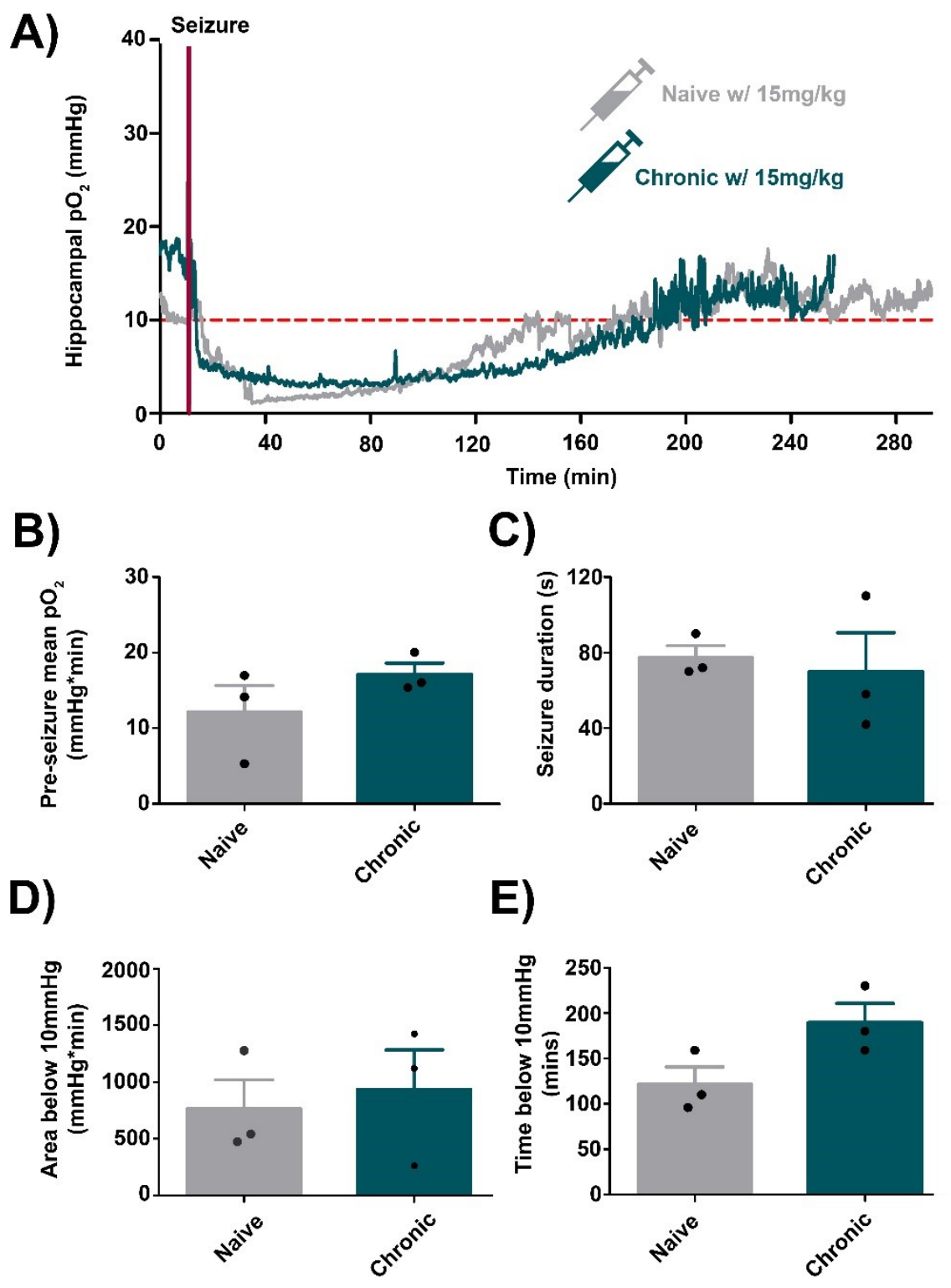

\section{Figure 2.8: Caffeine naïve rats compared to chronic caffeine rats}

(A) Mean $\mathrm{pO}_{2}$ line tracings displaying naïve rats $(\mathrm{n}=3)$ hippocampal oxygen vs rats after a subchronic (15 days) of caffeine administration $(\mathrm{n}=3)$. (B) Mean $\mathrm{pO}_{2}$ before seizure onset, no significant differences were found (C) Seizure duration, no significant differences were found (D) Quantification of (A) no significant reduction was found in the area below $10 \mathrm{mmHg}$ (E) The time spent below $10 \mathrm{mmHg}$, naïve rats and sub-chronic rats showed no significant difference. (Unpaired t-test) Data displayed are means \pm SEM. 


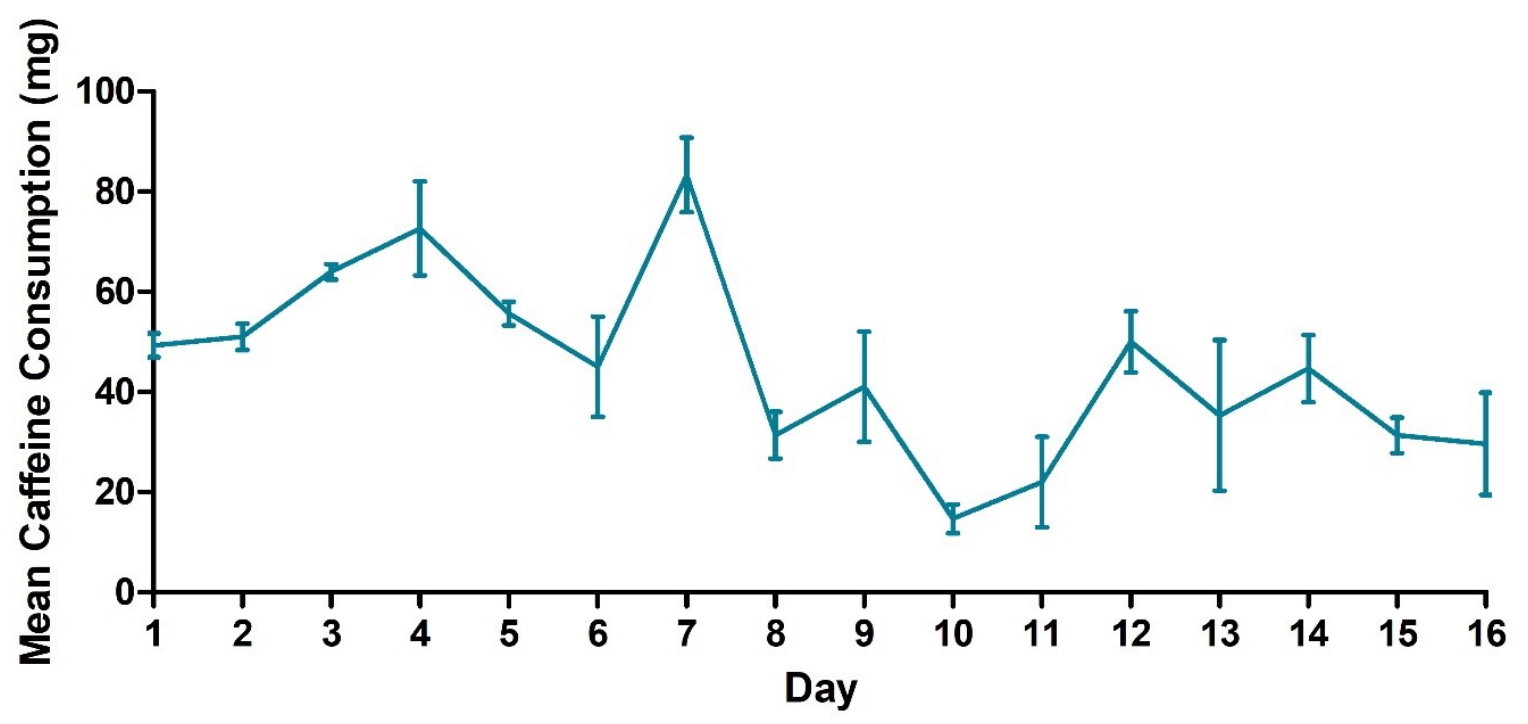

Figure 2.9 Mean consumption of caffeine throughout the chronic experiment Denotes the mean caffeine consumed as denoted as $(\mathrm{mg})$, significant differences were found between days $(\mathrm{F}(15,2)=9.72, * * * \mathrm{P}<0.0001$, repeated measure ANOVA). 


\subsubsection{Discussion}

Caffeine prolongs the time and area below the severe critical threshold (below $10 \mathrm{mmHg}$ ). This metric of below $10 \mathrm{mmHg}$ of oxygen has been demonstrated to cause significant changes to cellular physiology. Indeed, hypoxia dependent gene expression starts to occur via hypoxiainducible factor 1 alpha when $\mathrm{pO}_{2}$ falls below $10 \mathrm{mmHg}$ (Jiang et al., 1996). The depth and duration of severe hypoxia (below $10 \mathrm{mmHg}$ ) following brain injury can be used as a clinical predictor of outcomes for persons following brain injury (Maloney-Wilensky et al., 2009). Indeed, post brain injury the greater amount of time below $10 \mathrm{mmHg}$ results in increased risk of death (Van den Brink et al., 2000). For these reasons the severe critical threshold (or below $10 \mathrm{mmHg}$ ) is the metric used to define PIH.

Acute dosages of $15.0 \mathrm{mg} / \mathrm{kg}$ of caffeine caused a $30 \%$ drop in hippocampal $\mathrm{pO}_{2}$. This data coincides with prior research that found a $\sim 30 \%$ drop in cerebral oxygen in human caffeine drinkers (Addicott et al., 2009). In relation to PIH, an acute dosage of $15.0 \mathrm{mg} / \mathrm{kg}$ in rodents increases the area and time below the severe hypoxic threshold and a dosage of $10.0 \mathrm{mg} / \mathrm{kg}$ extends the postictal period. The dosage of $10.0 \mathrm{mg} / \mathrm{kg}$ in a rat is equivalent to $3.5 \mathrm{mg} / \mathrm{kg}$ in a human, which is approximately 2-3 cups of coffee for a 70kg human, when considering the metabolic differences between species (Ohta et al., 2007).

Caffeine's major metabolites share similar mechanisms of action (such as inhibition of adenosine receptors) and so should prolong hypoxia. Paraxanthine, caffeine's major metabolites, while not causing a drop-in pre-seizure hippocampal $\mathrm{pO}_{2}$, did cause a significant increase the area below severe hypoxic threshold. Paraxanthine prolonged postictal hypoxia period at $1 \mathrm{mg} / \mathrm{kg}$, this is interesting, however, as caffeine did not at $5 \mathrm{mg} / \mathrm{kg}$, as paraxanthine is $82 \%$ of the metabolic product of caffeine (Guerreiro et al. 2008), this should have resulted in $4.2 \mathrm{mg} / \mathrm{kg}$ of 
paraxanthine; we suspect this may be due to caffeine exerting a multitude of effects on various receptors, perhaps offsetting the effects of caffeine at higher dosages. While caffeine's minor metabolite theophylline caused a significant drop in pre-seizure hippocampal $\mathrm{pO}_{2}$. Interestingly, all the metabolites increase the time below the severe hypoxic threshold. Caffeine effects oxygen profiles for up to five hours, despite only having a half-life of 0.7-1 hour in rats (Bonati et al., 1984). These metabolites likely act in conjunction with caffeine to continually antagonize adenosine receptors, explaining how caffeine exerts an effect on hippocampal $\mathrm{pO}_{2}$ for around five hours.

Caffeine is an antagonist to the adenosine receptor family. Importantly, adenosine is largely released after seizures and is referred to as a natural anticonvulsant (Lee, Schubert, \& Heinemann, 1984; Dragunow, Goddard, \& Laverty, 1985; Boison 2008). Indeed, in human's extracellular adenosine levels increased by 6 - to 31 -fold with a significantly greater increase in the epileptogenic hippocampus minutes after seizure onset (During \& Spencer, 1992). One key adenosine receptor is the A1 receptor, found ubiquitously throughout the body and commonly found throughout cerebral vasculature (Echeverri et al., 2010). A1 receptors are G coupled i/o receptors that cause vasoconstriction when activated under physiological conditions. The selective A1 agonist, n6-cyclopentyladenosine caused a significant decrease in pre-seizure hippocampal pO2 and prevented recovery of postictal hypoxia. It could be that the adenosine released following seizures may activate A1 receptors, engaging vasculature to constrict, ultimately contributing to the prevention of local oxygen delivery. However, the antagonist DPCPX had no effects on pre-seizure hippocampal $\mathrm{pO}_{2}$ or postictal hypoxia duration. This is surprising, as caffeine acts as a competitive antagonist, and so should alleviate the adenosine induced vasoconstriction. Of note to this experiment, adenosine is upregulated in hippocampal 
epileptic tissue (During \& Spencer, 1992), and A1 receptors have been shown to decrease in density in the hippocampus of kindled rats (Rebola et al., 2003). However, as other adenosine receptors (A2A and A2B) act to vasodilate under physiological conditions, and as caffeine acts as a general antagonist to all adenosine receptors, it may be that the other adenosine receptors can not act to vasodilate when antagonized by caffeine. Indeed, all other adenosine receptors may (A2A, A2B) act in competition to A1 receptors to modulate vascular tone. Future studies should have a combination of adenosine agonists and antagonists to determine the exact interplay between the adenosine receptors on vasculature. Further, adenosine agonists and antagonists should be administered with caffeine to determine if it can alleviate caffeine's effects on preseizure $\mathrm{pO}_{2}$ and $\mathrm{PIH}$.

The second adenosine receptor A2A, a G-coupled s receptor, is known to cause vasodilation under physiological conditions. When the $\mathrm{A} 2 \mathrm{~A}$ receptor was antagonised by selective $\mathrm{SCH}-58261$, it resulted in a significant drop in pre-seizure baseline $\mathrm{pO}_{2}$, an effect also observed with caffeine, however, it had no effect on the area or time below the severe hypoxic threshold. This suggests that A2A when antagonized is responsible for the reduction of preseizure hippocampal $\mathrm{pO}_{2}$. Regardless, as $\mathrm{SCH}-58261$ has a short half-life, 26.7 minutes in rats, (Yang et al., 2007), it may be metabolized too quickly to exert effects on A2A, unlike caffeine and which in rats has a half-life of 0.7-1 hour in rats (Bonati et al., 1984). Future studies should use a higher dosage of SCH-58261 or inject at a time point sooner to seizure elicitation. This continued action of caffeine, and the metabolites of caffeine, on the A2A receptor could explain the decrease in vasculature tone. The last receptor we investigated was the A2B receptor, another G-coupled s receptor, while known to conventionally cause vasodilation, showed no significant effects with selective agonists or antagonists. 
Interestingly, impaired clearance of adenosine has been proposed as a potential mechanism for sudden unexpected death in epilepsy (SUDEP). The adenosine model of SUDEP suggests that increased adenosine levels over stimulates A1 and A2A in the brainstem, causing respiratory and cardiovascular collapse (Shen \& Boison, 2010). In fact, caffeine prolonged the lives of SUDEP model mice. In relation to our PIH model, it may be that the excess of adenosine found after seizures may act on A1 receptors to cause vasoconstriction, dropping oxygen levels below the critical hypoxic threshold, causing network dysfunction, thus causing respiratory collapse.

We also investigated caffeine's effect on intracellular calcium release via ryanodine receptors, using dantrolene to antagonize ryanodine receptors thus decreasing intracellular calcium. However, dantrolene showed no effects on hippocampal oxygen, this may due to it not effectively crossing the blood brain barrier (Muehlschlegel \& Sims, 2009). Further, it is important to note that many key targets of caffeine have already been investigated in relation to PIH in Farrell et al. (2016). While caffeine has been shown to generally cause vasodilation in the periphery, and has many molecular targets that should alleviate PIH, such as L-type calcium inhibition, or IP3 receptor inhibition, it ultimately prolongs the postictal period. This is consistent with prior findings in PIH, as drugs that conventionally cause vasodilation under physiological conditions fail to do so in structures undergoing PIH (Farrell et al., 2016).

Importantly, the distribution of adenosine receptors are found in different quantities throughout the brain, and so caffeine may cause different vasculature responses outside the hippocampal structure we investigated here (Poulsen \& Quinn 1998). A1 receptors for example, are found throughout the brain, but are found in higher levels throughout the hippocampus and cerebellar cortex (Goodman and Snyder, 1982; Fastbom et al., 1987). Caffeine has also been 
demonstrated to have different vascular actions in different brain regions, including vasodilation and vasoconstriction (Fredholm 1999).

The dosage used in our chronic study, $1.0 \mathrm{~g} /$ liter, is equivalent to drinking five cups of coffee a day in human adult (Yamakawa et al., 2017). While rats showed no change in preseizure $\mathrm{pO} 2$, or PIH profiles, they later showed an increase in the area below 10 on day 15. Rats also failed to develop tolerance to an acute caffeine injection $(15.0 \mathrm{mg} / \mathrm{kg})$, with their period of postictal hypoxia being equivalent to naïve rats when administered caffeine. This data corresponds to human data that showed a $30 \%$ drop in chronic caffeine drinkers' cerebral blood flow, suggesting a limited ability for the cerebral vasculature adenosine system to compensate (Addicott et al., 2009).

We acknowledge that one weakness of this study is animals sleep-wake cycles were not monitored over the course of chronic administration. As rats were administered the equivalent of 11 cups of coffee a day, the rats sleep cycle was most likely interrupted. As poor sleep can lead to a myriad of consequences, both physiological and behavioural, the effects of caffeine on prolonging PIH may be due not to the effects of caffeine directly, but rather due to causing sleep deprivation. Future studies should monitor rats to control for sleep-wake cycle disruptions. Further, we acknowledge that rats drank differing quantities of caffeine, resulting in a differing dosage across the chronic experiment.

Caffeine has been shown in imaging studies to lower cerebral baseline oxygen, while increasing the blood-oxygenation level-dependent (BOLD) responses. In one study, caffeine reduced cerebral perfusion by $13.2 \%$ without affecting cognitive performance (Mulderink et al., 2002). Caffeine at a $200 \mathrm{mg}$ dose increased the amplitude of the BOLD response by $37 \%$ in response to brief 2-s stimuli (Mulderink, Gitelman, Mesulam, Parrish, 2002). Caffeine can be 
used as a contrast booster, by lowering baseline levels of blood flow, researchers saw an increase in the BOLD response by $22-37 \%$ in visual cued motor tasks (Mulderink et al., 2002). Caffeine can also increase the linearity of the BOLD response and has been suggested for consideration when analysing rapid event-related fMRI studies (Liu, Liau 2010). While several drugs are considered during fMRI imaging, caffeine is often not. Here we suggest that a person's caffeine consumption should be considered during imaging. Alternatively, similarly to how caffeine can make the BOLD response more apparent, caffeine could be used in fMRI to highlight PIH, helping locate the focus of the seizure for surgical removal.

$\mathrm{PIH}$ is postulated to be responsible for the negative consequences associated with seizures, causing acute conditions (postictal symptoms) but also contributing to chronic conditions (interictal symptoms) (Farrell et al., 2017). As caffeine results in an increase in the time and area below the severe critical threshold after seizures, we suggest caffeine consumption paired with seizures will result in greater negative consequences than just seizures alone. Thus, it may be detrimental for persons with self-generating seizure disorders to consume caffeinated beverages. 


\section{Chapter Three: General Discussion}

\subsection{Summary}

The goal of this thesis was to evaluate the effects of commonly consumed drugs on seizureinduced hypoxia. PIH is theorized to contribute to various neurological consequences associated with seizures: acute, such as the postictal state, and chronic, such as interictal comorbidities (Farrell et al., 2017). The influence of commonly consumed drugs on PIH is important to establish, as persons are likely to have these drugs in their system during a seizure. Long-Evan rats were used to investigate the effects of four commonly consumed drugs (nicotine, ethanol, THC, caffeine) on hippocampal $\mathrm{pO}_{2}$ before and after a seizure. Following seizure elicitation in the hippocampus, PIH profiles worsened under only one commonly consumed drug: caffeine, the most commonly consumed drug in the world.

Caffeine increased the area and time below the severe hypoxic threshold post-seizure, but also caused a decrease in hippocampal oxygen pre-seizure. As caffeine adversely affected the PIH event, we sought to investigate the mechanisms involved. First, we examined the three major metabolites of caffeine: paraxanthine, theobromine, and theophylline. All three metabolites prolonged the PIH profile. As all the metabolites of caffeine antagonize adenosine receptors, we theorized that blockade of adenosine receptors may be responsible for the decrease in local hippocampal $\mathrm{pO}_{2}$.

We used a series of agonists and antagonists to determine the role of the $\mathrm{A} 1, \mathrm{~A} 2 \mathrm{~A}$ and $\mathrm{A} 2 \mathrm{~B}$ adenosine receptors in the onset and recovery of PIH. Surprisingly, the A1 agonist N-6, caused a significant drop in pre-seizure hippocampal $\mathrm{pO}_{2}$, followed by an increase in the area below the severe hypoxic threshold post-seizure. We suggest that the adenosine released after seizures, may be contributing to the onset of $\mathrm{PIH}$ by activating the A1 receptor. Conversely, the A2A selective 
antagonist $\mathrm{SCH} 58261$, caused a significant drop in pre-seizure hippocampal $\mathrm{pO}_{2}$. This suggests caffeine may prevent the A2A receptor from restoring vascular tone. We theorize that caffeine and its metabolites may continually antagonize A2A receptors to prevent recovery of local vasoconstriction after seizure. Interestingly, A2B appeared not be involved in PIH despite being known for modulation of vascular tone.

As persons who consume caffeine often do it daily, we sought to investigate how chronic caffeine consumption would affect the PIH profile. We theorized that rats on a chronic administration of caffeine may develop tolerance or sensitization to the effect of caffeine on the PIH profile. Rats did not develop tolerance throughout the time course of the experiment, but rather sensitization: on day 15 , rats showed an increase in the area below the severe hypoxic threshold. Further, when an acute high dose of caffeine was administered IP after 16 days of chronic caffeine administration, there was no significant difference to naïve rats receiving the same dosage. However, there was a trend suggesting chronic caffeine consumption may reduce the pre-seizure drop in local hippocampal $\mathrm{pO}_{2}$ when compared to acute administration, despite ultimately failing to protect from the effect of caffeine on the PIH profile.

\subsection{Future Directions}

To further determine how caffeine exerts its effects, adenosine receptor agonists and antagonists should be exhibited in combination with caffeine, as well as one another. For example, administration of A2A agonist, CGS 21680, in combination with caffeine may help determine if A2A antagonism is truly responsible for the effect of caffeine on PIH. Adenosine could also be administered via intra-cranial canula to determine its direct effect on PIH. Importantly, 
previously demonstrated treatment methods that alleviate PIH, such as nifedipine, should be administered alongside caffeine to determine if treatment is still viable after rats are administered caffeine.

Importantly, the distribution of adenosine receptors are not homogenously expressed throughout the brain, and so caffeine may cause different vasculature responses outside the hippocampal structure we investigated here (Poulsen \& Quinn 1998). Indeed, caffeine has been demonstrated to have different vascular actions in different brain regions, including vasodilation and vasoconstriction (Fredholm 1999). Future studies should examine the effect of caffeine on PIH regarding different brain structures, other than the hippocampus, to determine if the effect of caffeine on PIH is the same across epileptic foci.

Further, a novel SUDEP model implicates the A1 receptors in the brainstem (Shen, Li, Boison 2010). The adenosine SUDEP model suggests increased levels of adenosine released postseizure, result in dampening of network activity via synaptic A1 receptors. This then results in network dysfunction, and ultimately central apnea and suppression of cardiac function. Here we suggest that the proposed network dysfunction could be exacerbated by adenosine on A1 receptors located on smooth muscle; inducing local vasoconstriction and causing network dysfunction within the brainstem. In short, adenosine may contribute to the onset of SUDEP through smooth muscle and not only by synaptic A1 receptors.

Despite the negative consequences of caffeine in relation to PIH, effect of caffeine on hippocampal oxygen profiles may have some useful functions in future research and practice. Rats under high doses of caffeine alone (or even the A1 receptor agonist N-6) may fall below the severe hypoxic threshold, in the absence of seizures. In support of the PIH hypothesis, if oxygen drops below the severe hypoxic threshold on one of these drugs alone, they should exhibit the 
same behavioural deficits as found during PIH. These drugs would then control for seizure activity not being the cause behind the behavioural deficits, but rather the drop-in oxygen below the severe hypoxic threshold. Further, caffeine may have a use in imaging studies to "highlight" hypoxic structures post-seizure, helping to locate epileptic foci for surgical removal.

We also compared caffeine to three other commonly consumed drugs: nicotine, ethanol, THC (see Appendix A.1). However, unlike caffeine these drugs did not have any significant effect on pre-seizure baseline PO2, seizure duration, area or time below critical threshold for hypoxia. However, cigarette consumption has been shown to increase the clearance time of caffeine (Swanson, Lee, Hopp, 1994), while consumption of ethanol has shown to inhibit caffeine metabolism (George et al., 1986). As persons are likely to consume these drugs together, and not isolated, future research should examine these commonly consume drugs when administered in combination in relation to $\mathrm{PIH}$.

Importantly, clinical investigations into the effect of caffeine on postictal blood flow and postictal symptomology in persons with epilepsy are needed. As postictal hypoxia has been established in humans (Gaxiola-Valdex et al., 2017), future imaging studies should consider a person's caffeine intake. Indeed, typical imaging studies consider drug use, but often not caffeine. We hypothesis that if a person consumes caffeine before a seizure, it will result in a more severe PIH profile, a prolonged postictal state, and contribute chronically to anatomical abnormalities and interictal behavioral dysfunction. 


\subsection{Conclusions}

The postictal state is largely an overlooked aspect of epilepsy, defined by brain region specific impairments, ranging from amnesia to weakness. Indeed, postictal states results in reduced quality of life and are currently untreated. Caffeine prolongs PIH, and thus the postictal state. Moreover, acute high doses of caffeine caused severe hypoxia in the hippocampus of naïve rats without seizure activity. Acute high and medium dose caffeine exacerbated postictal hypoxia. The metabolites of caffeine also prolonged the time below the severe hypoxic threshold, theorized to work in conjunction with caffeine to prolong PIH. Caffeine and the three metabolites of caffeine, likely exerts effects through antagonizing the A2A receptor, worsening the $\mathrm{PIH}$ profile. Chronic caffeine consumption results in tolerance to the drop-in pre-seizure $\mathrm{pO}_{2}$ in the hippocampus but fails to protect from caffeine prolonging the PIH profile. Importantly, as caffeine is the most commonly consumed drug in the world, future clinical investigations are needed into the effect of caffeine on postictal blood flow and postictal symptomology. 


\section{Appendix: Unpublished data}

\section{A.1 Three commonly consumed drugs: Nicotine, Ethanol and THC in relation to PIH}

We sought to investigate if three commonly consumed drugs, nicotine, ethanol or THC would influence the postictal hypoxia profile. Rats $(\mathrm{N}=8)$ had an electrode and optrode implanted into the CA1 and CA3 hippocampus respectively. Rats had seizures elicited until they were established as reliably hypoxic. Rats then received kindling with local oxygen levels and electrical activity being simultaneously recorded before, and after seizures. Nicotine and ethanol were obtained from Cayman Chemicals. THC was obtained from Sigma Aldrich. Rats 30 minutes before seizure onset, were administered vehicle (DMSO) or nicotine $(\mathrm{n}=4)(0.25 \mathrm{mg} / \mathrm{kg}$, $0.50 \mathrm{mg} / \mathrm{kg}, 1.00 \mathrm{mg} / \mathrm{kg})$ or THC $(\mathrm{n}=5)(1.0 \mathrm{mg} / \mathrm{kg})$. For ethanol experiments, 10 minutes before seizure onset rats were administered vehicle (saline) or ethanol $(\mathrm{n}=4)(0.50 \mathrm{~g} / \mathrm{kg}, 1.00 \mathrm{~g} / \mathrm{kg}$, $2.00 \mathrm{~g} / \mathrm{kg}$ ). Rats local hippocampal oxygen profiles were measured to assess the influence of the commonly consumed drugs on postictal hypoxia. None of the drugs influenced postictal hypoxia profiles (Figure A.1), appearing to have no role in the onset or recovery of PIH. However, as nicotine and ethanol interact with caffeine, both shortening caffeine clearance time (Swanson, Lee, Hopp, 1994) and lengthening caffeine clearance time (George et al., 1986) respectively, future research should examine the combination of these drugs with caffeine on the PIH profile. 
A)

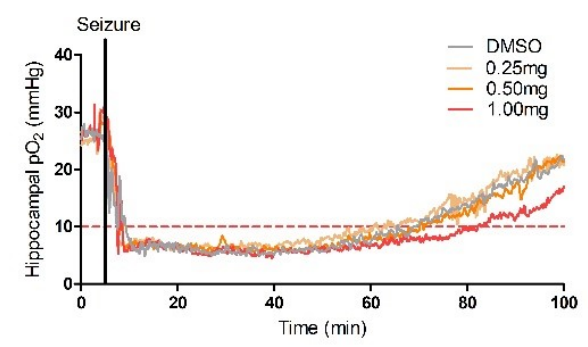

D)

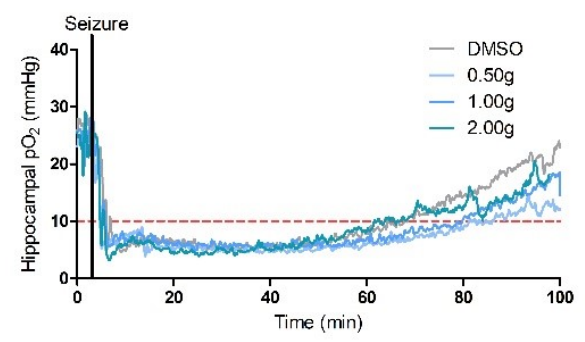

G)

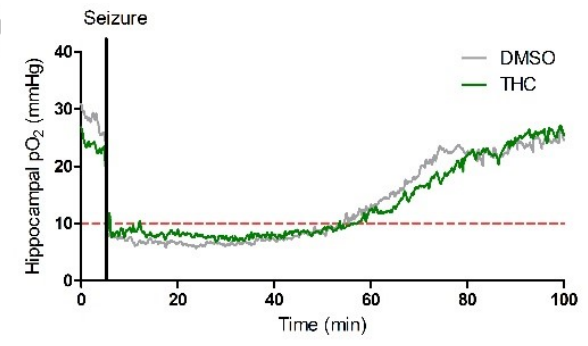

B)

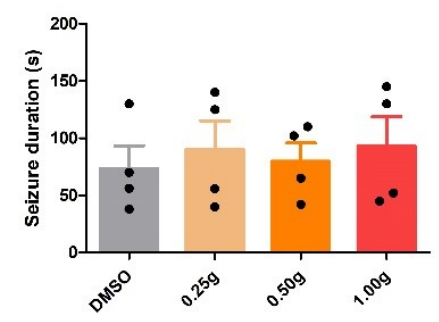

C)

E)

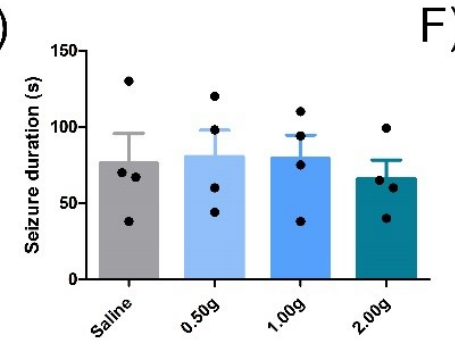

F)

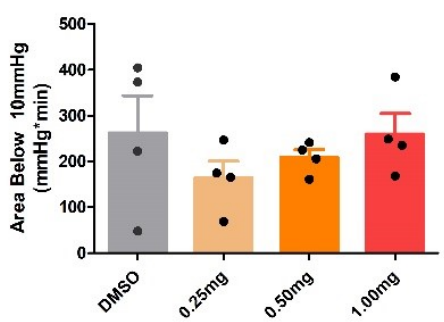

H)

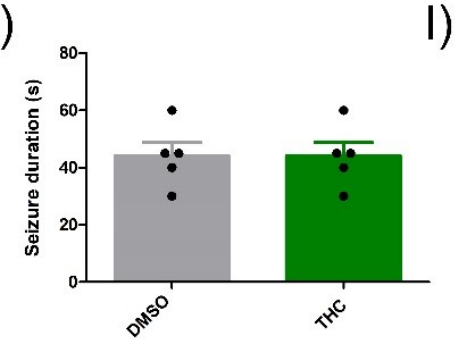

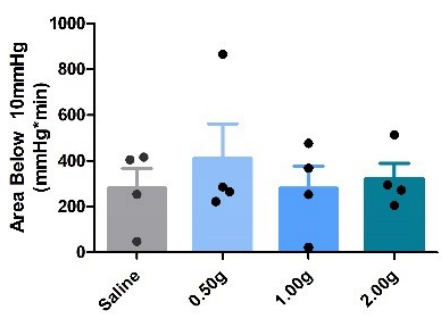

l)

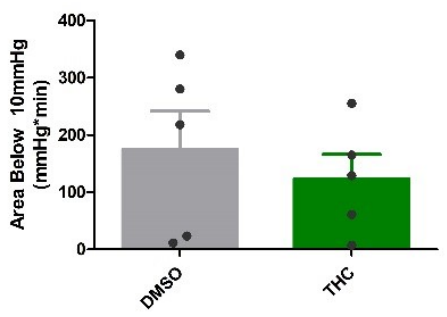

Figure A.1: Three commonly consumed drugs: Nicotine, Ethanol and THC have no relation to PIH

(A) Mean $\mathrm{pO}_{2}$ tracing of the rat hippocampus ( $\mathrm{n}=4$ ) following nicotine administration. (B) Rats seizure duration when administered nicotine, no significant differences were found $(\mathrm{F}(3,12)=0.17, \mathrm{p}>0.05$, ANOVA) (C) Quantification of (A), no significant differences were found. $\left(\mathrm{F}(3,12)=0.84, \mathrm{p}>0.05\right.$, ANOVA) (D) $\mathrm{Mean}_{\mathrm{pO}}$ tracing of the rat hippocampus $(\mathrm{n}=4)$ following ethanol IP injection. (E) No significant differences were found for seizure duration after ethanol administration. ( $\mathrm{F}(3,3)=0.1, \mathrm{p}>0.05$, ANOVA) (F) Quantification of (D), no significant differences were found $\left(\mathrm{F}(3,3)=0.47, \mathrm{p}>0.05\right.$, ANOVA) (G) Mean $\mathrm{pO}_{2}$ tracing of the rat hippocampus $(\mathrm{n}=5)$ following THC administration. (H) No significant differences were found for seizure duration after THC administration ( $p>0.05$, paired t-test) (I) Quantification of (G), no significant differences were found. ( $\mathrm{p}>0.05$, paired t-test) 


\section{A.2 Exogenous mixture of $5 \% \mathrm{CO}_{2}, 95 \% \mathrm{O}_{2}$ fails to alleviate PIH}

We sought to investigate if an exogenous mixture of 5\% carbon dioxide $\left(\mathrm{CO}_{2}\right)$ and $95 \%$ oxygen $\left(\mathrm{O}_{2}\right)$, or $100 \% \mathrm{O}_{2}$, could be a viable treatment to attenuate postictal hypoxia. $5 \% \mathrm{CO}_{2}$ has a potent vasodilatory action, and in combination with $95 \% \mathrm{O}_{2}$, may alleviate PIH (Figure A.2). Rats $(n=5)$ had an electrode and optrode implanted into the CA1 and CA3 hippocampus respectively. Rats had seizures elicited until they were established as reliably hypoxic. Rats then received kindling with local oxygen levels and electrical activity being simultaneously recorded before, and after seizures. Shortly after seizure termination, rats were placed in a chamber and administered atmospheric gasses (control group) or $5 \% \mathrm{CO}_{2}, 95 \% \mathrm{O}_{2}$ (experimental group) for 10 minutes. Rats received these gas mixtures without a seizure, immediately after seizure termination, or 20 minutes post seizure termination. Rats local hippocampal oxygen profiles were measured to assess the value of carbogen treatment. A mixture of $5 \% \mathrm{CO}_{2}, 95 \% \mathrm{O}_{2}$ or $100 \% \mathrm{O}_{2}$ resulted in a significant increase in hippocampal pO2 under physiological conditions (no seizure) but failed to alleviate $\mathrm{PIH} .5 \% \mathrm{CO}_{2}, 95 \% \mathrm{O}_{2}$ failed when administered immediately after seizure and 20 minutes post seizure. Further the vasodilatory mechanisms induced by hypercapnia have no role in the onset or recovery of PIH. 
A)

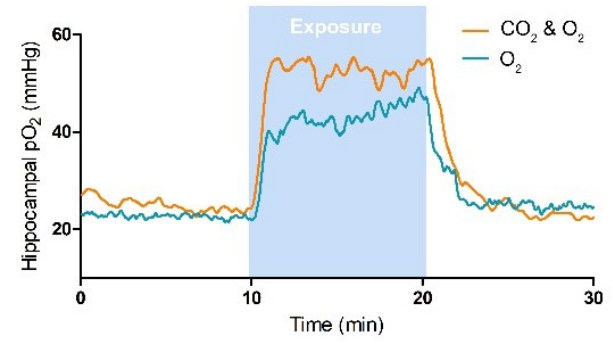

D)

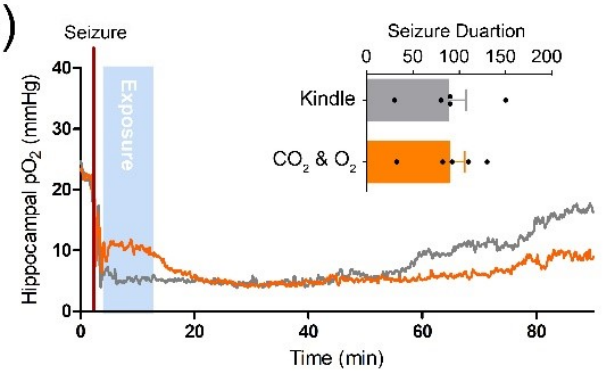

G)

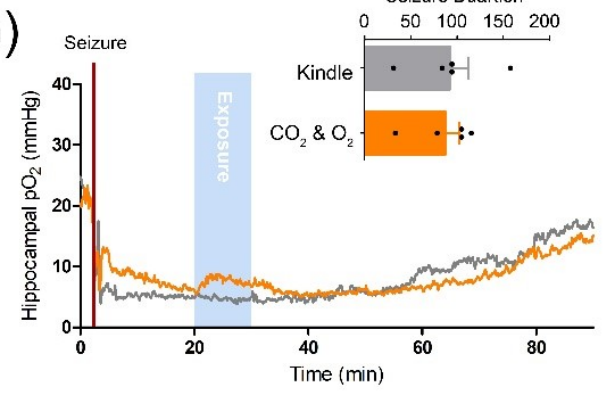

B)

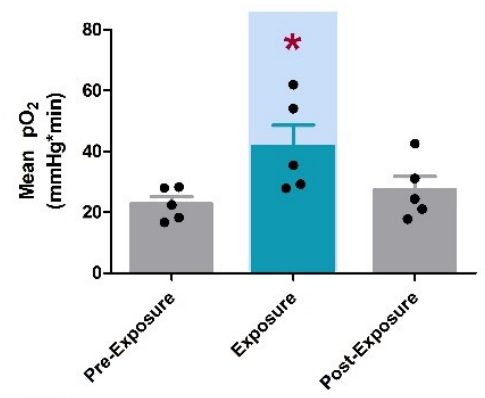

E)
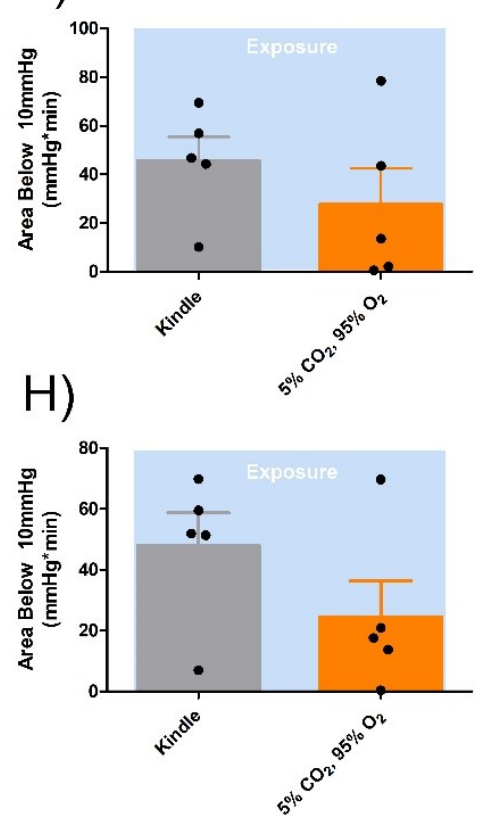

C)

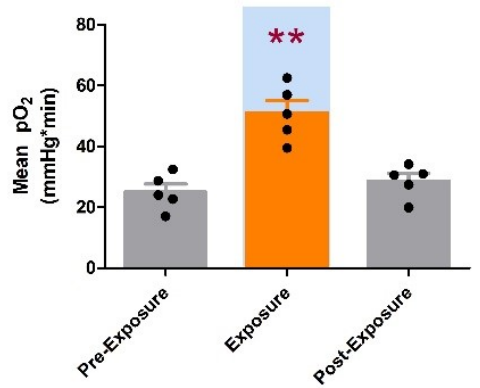

F)
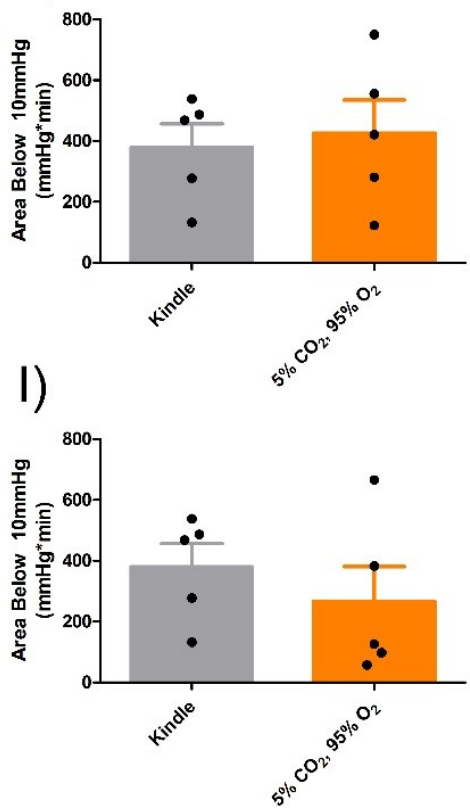

\section{Figure A.2: Exogenous mixture of 5\% $\mathrm{CO} 2,95 \% \mathrm{O} 2$ fails to alleviate PIH}

(A) The measurement of mean $\mathrm{pO}_{2}$ in the rat hippocampus $(\mathrm{n}=5)$ following exposure to both $100 \% \mathrm{O}_{2}$ and a gas mixture of $5 \% \mathrm{CO}_{2}$ and $95 \% \mathrm{O}_{2}$. Both gases significantly caused an elevation in hippocampal oxygen during exposure, when compared to pre-exposure. (B) Quantification of (A) for $100 \% \mathrm{O}_{2}$ treatment $* \mathrm{p}<0.05$ (paired t-test). (C) Quantification of (A) for $5 \% \mathrm{CO}_{2}$ and $95 \% \mathrm{O}_{2}$ treatment $* * \mathrm{p}<0.01$ (paired t-test). (D) Mean $\mathrm{pO}_{2}$ in the rat hippocampus following treatment of $\% \mathrm{CO}_{2}$ and $95 \% \mathrm{O}_{2}$ immediately after seizure termination. (E) Quantification of (D) during gas exposure. No significant differences were found. (F) Quantification of (D) of the area below 10 overall, no significant differences were found (G) Mean $\mathrm{pO}_{2}$ in the rat hippocampus $(\mathrm{n}=5)$ following treatment of $\% \mathrm{CO}_{2}$ and $95 \% \mathrm{O}_{2}, 20$ minutes post seizure onset. (H) Quantification of (G) during gas exposure, no significant differences were found (I) Quantification of $(\mathrm{G})$ overall. No significant differences were found. 


\section{References:}

Abad, R. S. C., Vilaplana, F. X. S., \& Fernandez, J. M. S. (2007). Genetic causes of epilepsy. The neurologist, 13(6), S47-S51.

Addicott, M. A., Yang, L. L., Peiffer, A. M., Burnett, L. R., Burdette, J. H., Chen, M. Y., ... \& Laurienti, P. J. (2009). The effect of daily caffeine use on cerebral blood flow: how much caffeine can we tolerate?. Human brain mapping, 30(10), 3102-3114.

Akula, K. K., Dhir, A., \& Kulkarni, S. K. (2008). Rofecoxib, a selective cyclooxygenase-2 (COX-2) inhibitor increases pentylenetetrazol seizure threshold in mice: possible involvement of adenosinergic mechanism. Epilepsy research, 78(1), 60-70.

Altura, B. M., \& Altura, B. T. (1982, June). Microvascular and vascular smooth muscle actions of ethanol, acetaldehyde, and acetate. In Federation proceedings (Vol. 41, No. 8, pp. 24472451).

Ambrose, J. A., \& Barua, R. S. (2004). The pathophysiology of cigarette smoking and cardiovascular disease: an update. Journal of the American college of cardiology, 43(10), 17311737.

Berg, A. T., Berkovic, S. F., Brodie, M. J., Buchhalter, J., Cross, J. H., van Emde Boas, W., ... \& Moshé, S. L. (2010). Revised terminology and concepts for organization of seizures and epilepsies: report of the ILAE Commission on Classification and Terminology, 2005-2009. Epilepsia, 51(4), 676-685.

Binder, D. K. (2004). A history of Todd and his paralysis. Neurosurgery, 54(2), 480-487.

Boison, D. (2008). Adenosine as a neuromodulator in neurological diseases. Current opinion in pharmacology, 8(1), 2-7.

Bonati, M., Latini, R., Tognoni, G., Young, J. F., \& Garattini, S. (1984). Interspecies comparison of in vivo caffeine pharmacokinetics in man, monkey, rabbit, rat and mouse. Drug metabolism reviews, 15(7), 1355-1383.

Borea, P. A., Varani, K., Vincenzi, F., Baraldi, P. G., Tabrizi, M. A., Merighi, S., \& Gessi, S. (2015). The A3 adenosine receptor: history and perspectives. Pharmacological reviews, 67(1), 74-102.

Buisson, A., Plotkine, M., \& Boulu, R. G. (1992). The neuroprotective effect of a nitric oxide inhibitor in a rat model of focal cerebral ischaemia. British journal of pharmacology, 106(4), 766-767.

Cadieux, J. S., Leclerc, P., St-Onge, M., Dussault, A. A., Laflamme, C., Picard, S., \& Pouliot, M. (2005). Potentiation of neutrophil cyclooxygenase-2 by adenosine: an early anti-inflammatory signal. Journal of cell science, 118(7), 1437-1447.

Cameron, O. G., Modell, J. G., \& Hariharan, M. (1990). Caffeine and human cerebral blood flow: a positron emission tomography study. Life sciences, 47(13), 1141-1146. 
Chakrabarti, A., Saini, H. K., \& Garg, S. K. (1998). Dose-finding study with nimodipine: a selective central nervous system calcium channel blocker on aminophylline induced seizure models in rats. Brain research bulletin, 45(5), 495-499.

Dai, S. S., Zhou, Y. G., Li, W., An, J. H., Li, P., Yang, N. \& Shen, H. Y. (2010). Local glutamate level dictates adenosine $\mathrm{A} 2 \mathrm{~A}$ receptor regulation of neuroinflammation and traumatic brain injury. Journal of Neuroscience, 30(16), 5802-5810.

Daly JW, Butts-Lamb P, and Padgett W. Subclasses of adenosine receptors in the central nervous system: Interaction with caffeine and related methylxanthines. Cell Mol Neurobiol. 1983. 1: 6980.

Daly, J. W. (1982). Adenosine receptors: targets for future drugs. Journal of medicinal chemistry, 25(3), 197-207.

Daly, J. W., Shi, D., Nikodijevic, O., \& Jacobson, K. A. (1999). The role of adenosine receptors in the central action of caffeine. Caffeine and behavior current views and research trends. CRC, Boca Raton, 1.

Deitrich, R. A., Dunwiddie, T. V., Harris, R. A., \& Erwin, V. G. (1989). Mechanism of action of ethanol: initial central nervous system actions. Pharmacological Reviews, 41(4), 489-537.

Delanty, N., Vaughan, C. J., \& French, J. A. (1998). Medical causes of seizures. The Lancet, 352(9125), 383-390.

Devinsky, O., Kelley, K., \& Yacubian, E. M. (1994). Postictal behavior. Arch Neurol, 51, 254259.

Dragunow, M., Goddard, G. V., \& Laverty, R. (1985). Is adenosine an endogenous anticonvulsant? Epilepsia, 26(5), 480-487.

During, M. J., \& Spencer, D. D. (1992). Adenosine: a potential mediator of seizure arrest and postictal refractoriness. Annals of neurology, 32(5), 618-624.

Echeverri, D., Montes, F. R., Cabrera, M., Galán, A., \& Prieto, A. (2010). Caffeine's vascular mechanisms of action. International journal of vascular medicine, 2010.

Essayan, D. M. (2001). Cyclic nucleotide phosphodiesterases. Journal of Allergy and Clinical Immunology, 108(5), 671-680.

Farrar, J. K. (1991). Tissue PO2 threshold of ischemic cell damage following MCA occlusion in cats. J Cereb Blood Flow Metab, 11(Suppl 2), S553.

Farrell, J. S., Colangeli, R., Wolff, M. D., Wall, A. K., Phillips, T. J., George, A., Federico P. \& G. C. Teskey, (2017). Postictal hypoperfusion/hypoxia provides the foundation for a unified theory of seizure-induced brain abnormalities and behavioral dysfunction. Epilepsia, 58(9), 1493-1501.

Farrell, J.S., I. Gaxiola-Valdez, M.D. Wolff, L.S. David, H.I. Dika, B.L. Geeraert, X.R. Wang, S. Singh, S.C. Spanswick, J.F. Dunn, M.C. Antle, P. Federico, G.C. Teskey. (2016) Postictal behavioural impairments are due to a severe prolonged hypoperfusion/hypoxia event that is COX-2 dependent. eLife 5: e19352 1-24 
Fernández-Dueñas, V., Gómez-Soler, M., López-Cano, M., Taura, J. J., Ledent, C., Watanabe, M., \& Ciruela, F. (2014). Uncovering caffeine's adenosine A2A receptor inverse agonism in experimental parkinsonism. ACS chemical biology, 9(11), 2496-2501.

Fiebich, B. L., Biber, K., Lieb, K., Van Calker, D., Berger, M., Bauer, J., \& Gebicke-Haerter, P. J. (1996). Cyclooxygenase-2 expression in rat microglia is induced by adenosine A2areceptors. Glia, 18(2), 152-180.

Fiest KM, Birbeck GL, Jacoby A, Jette N (2014). Stigma in Epilepsy. Current Neurology ad Neuroscience Reports, 14: 444.

Fisher, R. S., Acevedo, C., Arzimanoglou, A., Bogacz, A., Cross, J. H., Elger, C. E., \& Hesdorffer, D. C. (2014). ILAE official report: a practical clinical definition of epilepsy. Epilepsia, 55(4), 475-482.

Fisher, R. S., Boas, W. V. E., Blume, W., Elger, C., Genton, P., Lee, P., \& Engel, J. (2005). Epileptic seizures and epilepsy: definitions proposed by the International League Against Epilepsy (ILAE) and the International Bureau for Epilepsy (IBE). Epilepsia, 46(4), 470-472.

Fredholm, B. B., Bättig, K., Holmén, J., Nehlig, A., \& Zvartau, E. E. (1999). Actions of caffeine in the brain with special reference to factors that contribute to its widespread use. Pharmacological reviews, 51(1), 83-133.

Gale, S. D., \& Hopkins, R. O. (2004). Effects of hypoxia on the brain: neuroimaging and neuropsychological findings following carbon monoxide poisoning and obstructive sleep apnea. Journal of the International Neuropsychological Society, 10(1), 60-71.

George, J., Murphy, T., Roberts, R., Cooksley, W. G. E., Halliday, J. W., \& Powell, L. W. (1986). Influence of alcohol and caffeine consumption on caffeine elimination. Clinical and experimental pharmacology and physiology, 13(10), 731-736.

Gibbs, F. A., Lennox, W. G., \& GIBBS, E. L. (1934). Cerebral blood flow preceding and accompanying epileptic seizures in man. Archives of Neurology \& Psychiatry, 32(2), 257-272.

Gouder, N., Fritschy, J. M., \& Boison, D. (2003). Seizure suppression by adenosine A1 receptor activation in a mouse model of pharmacoresistant epilepsy. Epilepsia, 44(7), 877-885.

Graham, J. D. P., \& Li, D. M. F. (1973). Cardiovascular and respiratory effects of cannabis in cat and rat. British journal of pharmacology, 49(1), 1-10.

Grotenhermen, F. (2003). Pharmacokinetics and pharmacodynamics of cannabinoids. Clinical pharmacokinetics, 42(4), 327-360.

Guivernau, M., Baraona, E., \& Lieber, C. S. (1987). Acute and chronic effects of ethanol and its metabolites on vascular production of prostacyclin in rats. Journal of Pharmacology and Experimental Therapeutics, 240(1), 59-64.

Gunzerath, L., Faden, V., Zakhari, S., \& Warren, K. (2004). National Institute on Alcohol Abuse and Alcoholism report on moderate drinking. Alcoholism: Clinical and Experimental Research, 28(6), 829-847.

Hauser, W. A., Annegers, J. F., \& Kurland, L. T. (1993). Incidence of epilepsy and unprovoked seizures in Rochester, Minnesota: 1935-1984. Epilepsia, 34(3), 453-458. 
Hawke, T. J., Allen, D. G., \& Lindinger, M. I. (2000). Paraxanthine, a caffeine metabolite, dose dependently increases [Ca2+] i in skeletal muscle. Journal of Applied Physiology, 89(6), 23122317.

Helmstaedter, C., Elger, C. E., \& Lendt, M. (1994). Postictal courses of cognitive deficits in focal epilepsies. Epilepsia, 35(5), 1073-1078.

Hermann, B., \& Jacoby, A. (2009). The psychosocial impact of epilepsy in adults. Epilepsy \& behavior, 15(2), S11-S16.

Hla, T., \& Neilson, K. (1992). Human cyclooxygenase-2 cDNA. Proceedings of the National Academy of Sciences, 89(16), 7384-7388.

Hughes, A. D., Hering, S., \& Bolton, T. B. (1990). The action of caffeine on inward barium current through voltage-dependent calcium channels in single rabbit ear artery cells. Pflügers Archiv, 416(4), 462-466.

Járai, Z., Wagner, J. A., Varga, K., Lake, K. D., Compton, D. R., Martin, B. R., \& Razdan, R. K. (1999). Cannabinoid-induced mesenteric vasodilation through an endothelial site distinct from CB1 or CB2 receptors. Proceedings of the National Academy of Sciences, 96(24), 14136-14141.

Jiang B-H, Semenza GL, Bauer C, Marti HH. Hypoxia-inducible factor 1 levels vary 830 exponentially over a physiologically relevant range of $\mathrm{O} 2$ tension. Am. J. Physiol 831 1996;271:C1172-C1180

Jiang, W., Babyak, M., Krantz, D. S., Waugh, R. A., Coleman, R. E., Hanson, M. M., ... \& Blumenthal, J. A. (1996). Mental stress-induced myocardial ischemia and cardiac events. Jama, 275(21), 1651-1656.

Johansson, B., Ahlberg, S., van der Ploeg, I., Brené, S., Lindefors, N., Persson, H., \& Fredholm, B. B. (1993). Effect of long term caffeine treatment on A 1 and A 2 adenosine receptor binding and on mRNA levels in rat brain. Naunyn-Schmiedeberg's archives of pharmacology, 347(4), 407-414.

Josephson, Colin B., Jordan DT Engbers, Tolulope T. Sajobi, Nathalie Jette, Yahya Agha-Khani, Paolo Federico, William Murphy, Neelan Pillay, and Samuel Wiebe. (2016) An investigation into the psychosocial effects of the postictal state: neurology 10-1212.

Juergens, U. R., Degenhardt, V., Stöber, M., \& Vetter, H. (1999). New insights in the bronchodilatory and anti-inflammatory mechanisms of action of theophylline. Arzneimittelforschung, 49(08), 694-698.

Kanemoto, K., Tadokoro, Y., \& Oshima, T. (2010). Violence and postictal psychosis: a comparison of postictal psychosis, interictal psychosis, and postictal confusion. Epilepsy \& Behavior, 19(2), 162-166.

Kanner, A. M., Barry, J. J., Gilliam, F., Hermann, B., \& Meador, K. J. (2010). Anxiety disorders, subsyndromic depressive episodes, and major depressive episodes: do they differ on their impact on the quality of life of patients with epilepsy?. Epilepsia, 51(7), 1152-1158. 
Kaufman, K. R., \& Sachdeo, R. C. (2003). Caffeinated beverages and decreased seizure control. Seizure, 12(7), 519-521.

Khan S., Subota A., Sudershan S., Lukmanji A., Branch C., Roach P., Jette N., Wiebe S., Buchalter J., Federico P., Teskey G.C, Josephson C. (2018) Biomarkers of the post-ictal state: a systematic review and meta-analysis. Manuscript submitted for publication.

Klein, T., Shephard, P., Kleinert, H., \& Kömhoff, M. (2007). Regulation of cyclooxygenase-2 expression by cyclic AMP. Biochimica et Biophysica Acta (BBA)-Molecular Cell Research, 1773(11), 1605-1618.

Kitagawa H, Mori A, Shimada J, Mitsumoto Y, Kikuchi T. Intracerebral adenosine infusion improves neurological outcome after transient focal ischemia in rats. Neurol. Res. 2002;24:317323.

Kudo, R., Yuui, K., Kasuda, S., \& Hatake, K. (2015). Effect of alcohol on vascular function. Nihon Arukoru Yakubutsu Igakkai zasshi= Japanese journal of alcohol studies \& drug dependence, 50(3), 123-134.

Laurienti, P. J., Field, A. S., Burdette, J. H., Maldjian, J. A., Yen, Y. F., \& Moody, D. M. (2002). Dietary caffeine consumption modulates fMRI measures. Neuroimage, 17(2), 751-757.

Lee, D.S., Lee, S.K., Kim, S.-K., Kang, K.W., Lee, K.H., Hyun, I.Y., Chung, J.-K., and Lee, M.C. (1990). Late post-ictal residual perfusion abnormality in epileptogenic zone found on 6hour post-ictal SPECT. Neurology 55, 835-841.

Lee, K. S., Schubert, P., \& Heinemann, U. (1984). The anticonvulsive action of adenosine: a postsynaptic, dendritic action by a possible endogenous anticonvulsant. Brain research, 321(1), 160-164.

Leonardi, M., \& Ustun, T. B. (2002). The global burden of epilepsy. Epilepsia, 43(s6), 21-25

Leung, L. S., Ma, J., \& McLachlan, R. S. (2000). Behaviors induced or disrupted by complex partial seizures. Neuroscience \& Biobehavioral Reviews, 24(7), 763-775.

Li, W., Dai, S., An, J., Li, P., Chen, X., Xiong, R., ... \& Liu, X. (2008). Chronic but not acute treatment with caffeine attenuates traumatic brain injury in the mouse cortical impact model. Neuroscience, 151(4), 1198-1207.

Littleton, J. M., Little, H. J., \& Whittington, M. A. (1990). Effects of dihydropyridine calcium channel antagonists in ethanol withdrawal; doses required, stereospecificity and actions of Bay $\mathrm{K}$ 8644. Psychopharmacology, 100(3), 387-392.

Liu, T. T., \& Liau, J. (2010). Caffeine increases the linearity of the visual BOLD response. Neuroimage, 49(3), 2311-2317.

Liu, T. T., Behzadi, Y., Restom, K., Uludag, K., Lu, K., Buracas, G. T., \& Buxton, R. B. (2004). Caffeine alters the temporal dynamics of the visual BOLD response. Neuroimage, 23(4), 14021413. 
López-Gómez, M., Espinola, M., Ramirez-Bermudez, J., Martinez-Juarez, I. E., \& Sosa, A. L. (2008). Clinical presentation of anxiety among patients with epilepsy. Neuropsychiatric disease and treatment, 4(6), 1235.

MacEachern, S. J., D'Alfonso, S., McDonald, R. J., Thornton, N., Forkert, N. D., \& Buchhalter, J. R. (2017). Most children with epilepsy experience postictal phenomena, often preventing a return to normal activities of childhood. Pediatric neurology, 72, 42-50.

Magiorkinis, E., Sidiropoulou, K., \& Diamantis, A. (2010). Hallmarks in the history of epilepsy: epilepsy in antiquity. Epilepsy \& Behavior, 17(1), 103-108.

Maloney-Wilensky, E., Gracias, V., Itkin, A., Hoffman, K., Bloom, S., Yang, W., ... \& LeRoux, P. D. (2009). Brain tissue oxygen and outcome after severe traumatic brain injury: a systematic review. Critical care medicine, 37(6), 2057-2063.

Malpas, S. C., Robinson, B. J., \& Maling, T. J. (1990). Mechanism of ethanol-induced vasodilation. Journal of Applied Physiology, 68(2), 731-734.

Marangos, P. J., Boulenger, J. P., \& Patel, J. (1984). Effects of chronic caffeine on brain adenosine receptors: regional and ontogenetic studies. Life sciences, 34(9), 899-907.

Mathew, R. J., \& Wilson, W. H. (1986). Regional cerebral blood flow changes associated with ethanol intoxication. Stroke, 17(6), 1156-1159.

McIntyre, D. C., \& Gilby, K. L. (2009). Kindling as a model of human epilepsy. Canadian Journal of Neurological Sciences, 36.

Meliska, C. J., Landrum, R. E., \& Landrum, T. A. (1990). Tolerance and sensitization to chronic and subchronic oral caffeine: Effects of wheelrunning in rats. Pharmacology Biochemistry and Behavior, 35(2), 477-479.

Meyer, J. S., \& Portnoy, H. D. (1959). Post-epileptic paralysis A clinical and experimental study. Brain, 82(2), 162-185.

Minghetti, L., Greco, A., Potenza, R. L., Pezzola, A., Blum, D., Bantubungi, K., \& Popoli, P. (2007). Effects of the adenosine A2A receptor antagonist SCH 58621 on cyclooxygenase-2 expression, glial activation, and brain-derived neurotrophic factor availability in a rat model of striatal neurodegeneration. Journal of neuropathology and experimental neurology, 66(5), 363371.

Missiaen L., Parys J. B., De Smedt H., Himpens B., and Casteels R. (1994) “Inhibition of inositol trisphosphate-induced calcium release by caffeine is prevented by ATP," Biochemical Journal, vol. 300, no. 1, pp. 81-84, 1994.

Mitchell, D. C., Knight, C. A., Hockenberry, J., Teplansky, R., \& Hartman, T. J. (2014). Beverage caffeine intakes in the US. Food and Chemical Toxicology, 63, 136-142.

Monopoli, A., Lozza, G., Forlani, A., Mattavelli, A., \& Ongini, E. (1998). Blockade of adenosine A2A receptors by $\mathrm{SCH} 58261$ results in neuroprotective effects in cerebral ischaemia in rats. Neuroreport, $9(17), 3955-3958$. 
Morio, Y., \& McMurtry, I. F. (2002). Ca2+ release from ryanodine-sensitive store contributes to mechanism of hypoxic vasoconstriction in rat lungs. Journal of Applied Physiology, 92(2), 527534.

Muehlschlegel, S., \& Sims, J. R. (2009). Dantrolene: mechanisms of neuroprotection and possible clinical applications in the neurointensive care unit. Neurocritical care, 10(1), 103-115.

Mulderink, T. A., Gitelman, D. R., Mesulam, M. M., \& Parrish, T. B. (2002). On the use of caffeine as a contrast booster for BOLD fMRI studies. Neuroimage, 15(1), 37-44.

Muqaku, B., Tahir, A., Klepeisz, P., Bileck, A., Kreutz, D., Mayer, R. L., ... \& Gerner, C. (2016). Coffee consumption modulates inflammatory processes in an individual fashion. Molecular nutrition \& food research, 60(12), 2529-2541.

Nehlig, A. (1999). Cerebral energy metabolism and blood flow: useful tools for the understanding of the behavioral effects of caffeine. In Caffeine and behavior, current views and research trends (pp. 31-47). CRC Press Boca Raton, FL.

Newton, M. R., Berkovic, S. F., Austin, M. C., Rowe, C. C., McKay, W. J., \& Bladin, P. F. (1992). Postictal switch in blood flow distribution and temporal lobe seizures. Journal of Neurology, Neurosurgery \& Psychiatry, 55(10), 891-894.

Ohta, A., Lukashev, D., Jackson, E. K., Fredholm, B. B., \& Sitkovsky, M. (2007). 1, 3, 7trimethylxanthine (caffeine) may exacerbate acute inflammatory liver injury by weakening the physiological immunosuppressive mechanism. The Journal of Immunology, 179(11), 7431-7438.

Ortiz-Prado E, Natah S, Srinivasan S, Dunn JF. A method for measuring brain partial 908 pressure of oxygen in unanesthetized unrestrained subjects: the effect of acute and chronic 909 hypoxia on brain tissue pO2. J Neurosci Methods 2010;193:217-225.

Pacher, P., Bátkai, S., \& Kunos, G. (2005). Blood pressure regulation by endocannabinoids and their receptors. Neuropharmacology, 48(8), 1130-1138.

Penfield, W., von Sántha, K., \& Cipriani, A. (1939). Cerebral blood flow during induced epileptiform seizures in animals and man. Journal of Neurophysiology, 2(4), 257-267.

Pinel, J. P., \& Rovner, L. I. (1978). Experimental epileptogenesis: kindling-induced epilepsy in rats. Experimental neurology, 58(2), 190-202.

Poleszak, E., Szopa, A., Wyska, E., Kukuła-Koch, W., Serefko, A., Wośko, S., ... \& Wlaź, P. (2016). Caffeine augments the antidepressant-like activity of mianserin and agomelatine in forced swim and tail suspension tests in mice. Pharmacological Reports, 68(1), 56-61.

Poulsen, S. A., \& Quinn, R. J. (1998). Adenosine receptors: new opportunities for future drugs. Bioorganic \& medicinal chemistry, 6(6), 619-641.

Pulliainen, V., \& Jokelainen, M. (1995). Comparing the Cognitive Effects of Phenytoin and Carbamazepine in Long-Term Monotherapy: A Two-Year Follow-Up. Epilepsia, 36(12), 1195 1202.

Racine RJ (1972). Modification of seizure activity by electrical stimulation. II. Motor seizure. Electroencephalogr Clin Neurophysiol., 32(3): 281-294 
Rebola, N., Pinheiro, P. C., Oliveira, C. R., Malva, J. O., \& Cunha, R. A. (2003). Subcellular localization of adenosine A1 receptors in nerve terminals and synapses of the rat hippocampus. Brain research, 987(1), 49-58.

Reissig, C. J., Strain, E. C., \& Griffiths, R. R. (2009). Caffeinated energy drinks-a growing problem. Drug and alcohol dependence, 99(1-3), 1-10.

Ribeiro, J. A., \& Sebastiao, A. M. (2010). Caffeine and adenosine. Journal of Alzheimer's Disease, 20(S1), 3-15.

Rombo, D. M., Newton, K., Nissen, W., Badurek, S., Horn, J. M., Minichiello, L., ... \& Lamsa, K. P. (2015). Synaptic mechanisms of adenosine A2A receptor-mediated hyperexcitability in the hippocampus. Hippocampus, 25(5), 566-580.

Rudolphi, K. A., Schubert, P., Parkinson, F. E., \& Fredholm, B. B. (1992). Neuroprotective role of adenosine in cerebral ischaemia. Trends in pharmacological sciences, 13, 439-445.

Sastry, B. R., Hemontolor, M. E., \& Olenick, M. (1999). Prostaglandin E2 in human placenta: its vascular effects and activation of prostaglandin E2 formation by nicotine and cotinine. Pharmacology, 58(2), 70-86.

Sattin A. \& Rall, T. W. (1970). The effect of adenosine and adenine nucleotides on the cyclic adenosine 3', 5'-phosphate content of guinea pig cerebral cortex slices. Molecular Pharmacology, 6(1), 13-23.

Schindler, C. W., Karcz-Kubicha, M., Thorndike, E. B., Müller, C. E., Tella, S. R., Ferré, S., \& Goldberg, S. R. (2005). Role of central and peripheral adenosine receptors in the cardiovascular responses to intraperitoneal injections of adenosine A1 and A2A subtype receptor agonists. British journal of pharmacology, 144(5), 642-650.

Schwierin, B., Borbély, A. A., \& Tobler, I. (1996). Effects of N 6-cyclopentyladenosine and caffeine on sleep regulation in the rat. European journal of pharmacology, 300(3), 163-171.

Simpson, R. E., O'regan, M. H., Perkins, L. M., \& Phillis, J. W. (1992). Excitatory transmitter amino acid release from the ischemic rat cerebral cortex: effects of adenosine receptor agonists and antagonists. Journal of neurochemistry, 58(5), 1683-1690.

Stefanatos, A. K. (2015). Neurocognitive and psychosocial functions in children with frontal and temporal lobe epilepsy(Doctoral dissertation).

Stephen, L. J., \& Brodie, M. J. (2002). Seizure freedom with more than one antiepileptic drug. Seizure-European Journal of Epilepsy, 11(6), 349-351.

Subota A., Khan S,Josephson C., Manji S., Lukmanji S., Roach P., Wiebe S., Buchalter J., Federico P., Teskey G.C, Lorenzetti D., Jette N. (2018) Signs and Symptoms of the Post-Ictal State in Epilepsy: A Systematic Review and Meta-Analysis. Manuscript submitted for publication.

Swanson, J. A., Lee, J. W., \& Hopp, J. W. (1994). Caffeine and nicotine: a review of their joint use and possible interactive effects in tobacco withdrawal. Addictive behaviors, 19(3), 229-256. 
Teekachunhatean, S., Tosri, N., Rojanasthien, N., Srichairatanakool, S., \& Sangdee, C. (2013). Pharmacokinetics of caffeine following a single administration of coffee enema versus oral coffee consumption in healthy male subjects. ISRN pharmacology, 2013.

Tellez-Zenteno JF, Patten SB, Jette N, Williams J, Wiebe S (2007). Psychiatric comorbidity in epilepsy: A population-based analysis. Epilepsia, 48(12): 2336-2344.

Thithapandha, A., Maling, H. M., \& Gillette, J. R. (1972). Effects of caffeine and theophylline on activity of rats in relation to brain xanthine concentrations. Proceedings of the Society for Experimental Biology and Medicine, 139(2), 582-586.

Todd RB. (1849) On the pathology and treatment of convulsive diseases. London Medical Gazette.

Trincavelli, M. L., Melani, A., Guidi, S., Cuboni, S., Cipriani, S., Pedata, F., \& Martini, C. (2008). Regulation of A2A adenosine receptor expression and functioning following permanent focal ischemia in rat brain. Journal of neurochemistry, 104(2), 479-490.

Ukena, D., Schudt, C., \& Sybrecht, G. W. (1993). Adenosine receptor-blocking xanthines as inhibitors of phosphodiesterase isozymes. Biochemical pharmacology, 45(4), 847-851.

Umemura, T., Ueda, K., Nishioka, K., Hidaka, T., Takemoto, H., Nakamura, S., \& Yoshizumi, M. (2006). Effects of acute administration of caffeine on vascular function. American Journal of Cardiology, 98, 1538-1541.

Usachev, Y., Shmigol, A., Pronchuk, N., Kostyuk, P., \& Verkhratsky, A. (1993). Caffeineinduced calcium release from internal stores in cultured rat sensory neurons. Neuroscience, 57(3), 845-859.

Van den Brink, W. A., van Santbrink, H., Steyerberg, E. W., Avezaat, C. J., Suazo, J. A. C., Hogesteeger, C., \& Maas, A. I. (2000). Brain oxygen tension in severe head injury. Neurosurgery, 46(4), 868-878.

Ward BW, Schiller JS (2013). Prevalence of multiple chronic conditions among US adults: Estimates form the National Health Interview Survey, 2010. Preventing Chronic Disease, 10: 120203

Wesnes, K. A., Edgar, C., Dean, A. D. P., \& Wroe, S. J. (2009). The cognitive and psychomotor effects of remacemide and carbamazepine in newly diagnosed epilepsy. Epilepsy \& behavior, 14(3), 522-528.

Williams-Karnesky, R. L., \& Stenzel-Poore, M. P. (2009). Adenosine and stroke: maximizing the therapeutic potential of adenosine as a prophylactic and acute neuroprotectant. Current neuropharmacology, 7(3), 217-227.

World Health Organization, \& Research for International Tobacco Control. (2008). WHO report on the global tobacco epidemic, 2008: the MPOWER package. World Health Organization.

Yamakawa, G. R., Lengkeek, C., Salberg, S., Spanswick, S. C., \& Mychasiuk, R. (2017). Behavioral and pathophysiological outcomes associated with caffeine consumption and repetitive mild traumatic brain injury (RmTBI) in adolescent rats. PLoS one, 12(11), e0187218. 
Yang, M., Soohoo, D., Soelaiman, S., Kalla, R., Zablocki, J., Chu, N., ... \& Shryock, J. C. (2007). Characterization of the potency, selectivity, and pharmacokinetic profile for six adenosine A 2A receptor antagonists. Naunyn-Schmiedeberg's archives of pharmacology, 375(2), 133-144.

Yogi, A., Callera, G. E., Hipólito, U. V., Silva, C. R., Touyz, R. M., \& Tirapelli, C. R. (2010). Ethanol-induced vasoconstriction is mediated via redox-sensitive cyclo-oxygenase-dependent mechanisms. Clinical Science, 118(11), 657-668.

Young, D., \& Dragunow, M. (1994). Status epilepticus may be caused by loss of adenosine anticonvulsant mechanisms. Neuroscience, 58(2), 245-261. 